LUANA ESCHHOLZ BOMFIN

Avaliação dos parâmetros clínico, histopatológico e imunoistoquímico dos Tumores Odontogênicos Queratocísticos associados ou não à Síndrome do Carcinoma Nevóide Basocelular 


\title{
Avaliação dos parâmetros clínico, histopatológico e imunoistoquímico dos Tumores Odontogênicos Queratocísticos associados ou não à Síndrome do Carcinoma Nevóide Basocelular
}

\author{
Versão Corrigida \\ Dissertação apresentada à Faculdade de \\ Odontologia da Universidade de São \\ Paulo, para obter o título de Mestre, pelo \\ Programa de Pós-Graduação em \\ Odontologia. \\ Área de Concentração: Patologia bucal \\ Orientador: Prof. Dr. Fábio de Abreu \\ Alves
}

São Paulo 
Autorizo a reprodução e divulgação total ou parcial deste trabalho, por qualquer meio convencional ou eletrônico, para fins de estudo e pesquisa, desde que citada a fonte.

Catalogação-na-Publicação

Serviço de Documentação Odontológica

Faculdade de Odontologia da Universidade de São Paulo

\section{Bomfin, Luana Eschholz}

Avaliação dos parâmetros clínico, histopatológico e imunoistoquímico dos Tumores Odontogênicos Queratocísticos associados ou não à Síndrome do Carcinoma Nevóide Basocelular [versão corrigida] / Luana Eschholz Bomfin; orientador Fabio de Abreu Alves. -São Paulo, 2011.

70p. : fig., tab., $30 \mathrm{~cm}$.

Dissertação -- Programa de Pós-Graduação em Odontologia. Área de Concentração: Patologia Bucal. -- Faculdade de Odontologia da Universidade de São Paulo.

Versão corrigida de acordo com as sugestões da Banca Examinadora em 05/10/2011

1. Tumores odontogênicos - Avaliação. 2. Síndrome do Nevo Basocelular. 3. Patologia Bucal. I. Alves, Fábio de Abreu. II. Título. 
Bomfin LE. Avaliação dos parâmetros clínico, histopatológico e imunoistoquímico dos Tumores Odontogênicos Queratocísticos associados ou não à Síndrome do Carcinoma Nevóide Basocelular. Dissertação apresentada à Faculdade de Odontologia da Universidade de São Paulo para obtenção do título de Mestre em Odontologia.

Aprovado em: / /2011

\section{Banca Examinadora}

$\operatorname{Prof}(\mathrm{a}) . \operatorname{Dr}(\mathrm{a})$ Instituição:

Julgamento: Assinatura:

$\operatorname{Prof}(\mathrm{a}) . \operatorname{Dr}(\mathrm{a})$ Instituição:

Julgamento: Assinatura:

Prof(a). Dr(a). Instituição:

Julgamento: Assinatura: 
Dedico estes anos de estudo aos meus pais, Asiel e Márcia, que sempre me apoiaram em todas as decisões e continuam me incentivando nesta jornada.

Aos meus queridos avôs e avós, Asiel e Lourdes, Luis Carlos e Branca, que sempre apostaram no meu sucesso.

Ao Leonardo por compartilhar os momentos importantes e principalmente pelo amor e incentivo. 


\section{AGRADECIMENTOS}

Ao meu orientador, Prof. Dr. Fábio de Abreu Alves, por ter acreditado no meu trabalho e pela confiança depositada, nos quais tornaram possível a realização desta dissertação.

Ao Dr. Clóvis Antonio Lopes Pinto, patologista do Hospital AC Camargo, que contribuiu sabidamente para o desenvolvimento desta dissertação.

Ao Prof. Dr. Fábio Daumas Nunes pelas sugestões e colaboração na elaboração no estudo.

À Dra. Maria Isabel A. de S. Waddington Achatz e enfermeira Amanda do Departamento de Oncogenética do Hospital AC Camargo.

Aos amigos e colegas de pós-graduação Ana Paula Molina, Natalie Kelner, Elisângela Noborikawa, Rodrigo Nascimento Lopes, Gustavo Rabelo, Carla Siqueira, Gabriela Artico, Viviana Lanel, Michele Ramos e Aline Benevides pela amizade, companheirismo e incentivo na realização desta dissertação.

Aos amigos Fernanda Stabile, Alyne Rangifo, Vanessa, Graziella, Paulo, Carina, Gabriela e Jucelino.

Aos Drs. Danyel Elias da Cruz Perez, José Divaldo Prado e André Caroli Rocha pelos anos de aprendizado no Departamento de Estomatologia do Hospital AC Camargo.

Aos Professores Fernando Ricardo Xavier da Silveira e Dante Antonio Migliari por terem me recebido na Disciplina de Estomatologia que muito contribuiu com a minha formação.

Aos Professores e colegas da Disciplina de Estomatologia Clínica e da Disciplina de Patologia Bucal da Faculdade de Odontologia da USP.

À Aline Damascena que contribuiu com a análise estatística, à Sueli Nonogaki e ao Severino pela contribuição no laboratório para confecção das lâminas e realização das reações imunoistoquímicas.

À FAPESP - Fundação de Amparo à Pesquisa do Estado de São Paulo pela concessão da Bolsa de Estudos e Auxilio a Pesquisa.

Ciente de que seria impossível lembrar-se de todos que, direta ou indiretamente contribuíram de alguma forma para a realização deste trabalho, deixo aqui meus sinceros agradecimentos àqueles que fizeram parte de minha conquista. 


\section{RESUMO}

Bomfin LE. Avaliação dos parâmetros clínico, histopatológico e imunoistoquímico dos Tumores Odontogênicos Queratocísticos associados ou não à Síndrome do Carcinoma Nevóide Basocelular. [dissertação]. São Paulo: Universidade de São Paulo, Faculdade de Odontologia; 2011. Versão corrigida

Introdução. O Tumor Odontogênico Queratocístico (TOQC) é uma lesão de origem odontogênica que se apresenta exclusivamente nos ossos gnáticos e possui alto potencial de agressividade local. Pode estar associado à Síndrome do Carcinoma Nevóide Basocelular (SCNBC), que se caracteriza por apresentar inúmeras alterações de desenvolvimento, múltiplos carcinomas basocelulares (CBCs) além de anormalidades esqueléticas. Cerca de 65 a 100\% dos pacientes com a síndrome podem apresentar múltiplos TOQCs. Objetivo. Avaliar e correlacionar os achados clínicos, histopatológico e expressão imunoistoquímica (IQ) dos marcadores de prognóstico (p53 e ki-67) e de histogênese tumoral (Citoqueratinas 14, 17 e 19) em TOQCs associados ou não à SCNBC diagnosticados entre 1970 e 2009 no Hospital AC Camargo, São Paulo. Pacientes e Métodos. Estudo retrospectivo em que foram avaliados 74 pacientes, 60 não portadores da SCNBC (Grupo 1) e 14 portadores da SCNBC (Grupo 2). Os dados clínicos dos pacientes foram obtidos a partir dos prontuários médicos e sumarizados em fichas clínicas padronizadas para o estudo. Os pacientes do Grupo 1 apresentaram 61 TOQCs primários e 15 TOQCs recorrentes. O Grupo 2 apresentou 31 TOQCs primários e 8 recorrentes. Resultados. No Grupo 1, houve predomínio de pacientes nas $3^{\mathrm{a}}$ e $4^{\mathrm{a}}$ décadas de vida e no Grupo 2 , na $2^{\mathrm{a}}$ década $(\mathrm{p}=0.02)$. De acordo com o sexo, houve predileção pelas mulheres em ambos os Grupos (53,33\% no Grupo 1 e 64,29\% no Grupo 2). A mandíbula foi mais frequentemente acometida nos dois Grupos (81,96\% no Grupo 1 e 58,06\% no Grupo 2). Contudo, a discrepância em relação à distribuição entre mandíbula e maxila foi menor no Grupo 2 ( $\mathrm{p}=0.009)$. O padrão radiográfico multilocular foi mais frequente no Grupo 1 (39,34\%) e unilocular no Grupo 2 (48,39\%) ( $\mathrm{p}=0.008)$. A associação de enucleação e curetagem foi frequentemente realizada em ambos os Grupos (55,74\% no Grupo 1 e 96,78 no Grupo 2). A taxa de recorrência foi de $21,31 \%$ no Grupo 1 e $22,58 \%$ no Grupo 2. As manifestações clínicas mais comuns dos 
pacientes com SCNBC foram CBCs, calcificação da foice cerebral e “"“pits"” palmares. De acordo com a análise imunoistoquímica dos marcadores CQ 14, CQ 17, CQ 19, p53 e ki-67, não foram observadas diferenças no padrão de expressão entre os Grupos de TOQCs avaliados. Conclusões. Os TOQCs associados à SCNBC acometem mais frequentemente indivíduos do sexo feminino e em idade mais precoce do que os TOQCs esporádicos. Múltiplos TOQCs foram frequentemente observados em pacientes sindrômicos e consequentemente houve menor discrepância em relação à distribuição entre mandíbula e maxila. $\mathrm{O}$ aspecto radiográfico unilocular é mais frequente em TOQCs associados à SCNBC e multilocular em TOQCs esporádicos. As taxas de recorrências foram similares em TOQCs associados e não associados à SCNBC.

Palavras-chave: Queratocisto. Síndrome de Gorlin. Síndrome do Carcinoma Nevóide Basocelular. Tumor Odontogênico Queratocístico. 


\begin{abstract}
Bomfin LE. Evaluation of clinical, histopathological and immunohistochemistry parameters of Keratocystic Odontogenic Tumor associated or not with Nevoid Basal Cell Carcinoma Syndrome [dissertation]. São Paulo: Universidade de São Paulo, Faculdade de Odontologia; 2011. Versão corrigida
\end{abstract}

Introduction. Keratocystic odontogenic tumor (KCOT) is a lesion of odontogenic origin which arise exclusively in gnatic bones and demonstrates high potential of local aggressiveness. KCOT may be associated with Nevoid Basal Cell Carcinoma Syndrome (NBCCS) which is characterized by development defects, multiple basal cell carcinoma (BCC) and skeletal anomalies. Around 65 to $100 \%$ of patients with NBCCS present multiple KCOT affecting jaws. Objective. Evaluate clinical, histopathological and immunohistochemical (IHC) expression of prognostic markers (p53 and ki-67) and tumor histogenesis (citokeratin 14, 17 and 19) in KCOT associated or not to NBCCS diagnosed between 1970 and 2009 at AC Camargo Hospital (São Paulo). Patients and methods. Retrospective study which has evaluated 74 patients, being 60 not associated with NBCCS (Group 1) and 14 associated with NBCCS (Group 2). Clinical data of patients was obtained from medical charts and summarized into standardized records for this study. The patients of Group 1 presented 61 primary KCOT and 15 recurrent KCOT. Group 2 presented 31 primary KCOT and 8 recurrent KCOT. Results. In Group 1 , patients was frequently affected in $3^{\text {rd }}$ and $4^{\text {th }}$ decades and Group 2 , in $2^{\text {nd }}$ decade $(\mathrm{p}=$ 0.02). According to gender, a predilection for females was observed in both groups (53.33\% in Group 1 and 64.29\% in Group 2). The mandible was more affected in both Groups (81.96\% in Group 1 e 58.06\% in Group 2). However, the discrepancy regarding the distribution between mandible and maxilla was shorter in Group 2 ( $\mathrm{p}=0.009$ ). Radiographic pattern more observed was multilocular in Group 1 (39.34\%) and unilocular in Group $2(48.39 \%)(\mathrm{p}=0.008)$. The treatment mostly performed was association of enucleation and curettage in both Groups (55.74\% in Group 1 and 96.78 and Group 2). Recurrent rates were $21.31 \%$ in Group 1 and $22.58 \%$ in Group 2. Most clinical manifestations of NBCCS patient's beyond KCOT were BCC, falx cerebri calcification and palmar "pits". According to IHC analyses of Ck14, Ck 17, Ck19, p53 and ki-67, there were no differences of expression in all groups of KCOT evaluated. Conclusions. KCOT associated with NBCCS affects more commonly female 
individuals and in earlier age than in KCOT not related to NBCCS. Multiple KCOT were frequently observed in patients with NBCCS and consequently there was less discrepancy in relation to the distribution between maxilla and mandible. Multilocular pattern is more frequent in sporadic KCOT and unilocular in syndromic KCOT. Recurrence rates were similar in KCOT associated and not associated to NBCCS.

Key words: Keratocyst. Gorlin Syndrome. Nevoid basal cell carcinoma syndrome. Keratocystic odontogenic tumor. 


\section{LISTA DE FIGURAS}

Figura 2.1 - Via de sinalização do HH.

Figura 5.1 - Rx panorâmico: TOQC apresentando imagem radiolúcida multilocular em região anterior de mandíbula em paciente não portador da SCNBC. 37

Figura 5.2 - Rx panorâmico: TOQC apresentando 4 imagens radiolúcidas uniloculares, envolvendo $3^{\circ}$ molar incluso em paciente portador da SCNBC. 37

Figura 5.3 - Características histopatológicas dos TOQCs (HE). A. Cápsula cística revestida por epitélio pavimentoso estratificado paraqueratinizado exibindo 4 a 5 camadas de células. As células da camada basal são em paliçadas e a superfície corrugada. B. "Brotamento" das células epiteliais na cápsula cística. C. Células epiteliais odontogênicas presentes na cápsula fibrosa D.Presença de cisto satélite na cápsula cística....... .40

Figura 5.4 - Padrões de marcação das CQ 14, CQ 17 e 19 em TOQCs (IQ). A. Marcação basal da CQ 14 em TOQC não associado à SCNBC. B. Marcação das camadas basal, intermediária e superficial da CQ 17 em TOQC não associado à SCNBC. C. Marcação epitelial da CQ 17 predominantemente nas camadas basal e intermediária em TOQC não associado à SCNBC. D. Marcação epitelial da CQ 19 nas camadas intermediárias e superficiais em TOQC não associado à SCNBC

Figura 5.5 - Padrões de marcação do p53 e Ki-67 (IQ). A. Marcação do p53 em 36,57\% em TOQC não associado à SCNBC. B. Marcação do p53 de 61,29\% em TOQC associado à SCNBC. C. Marcação positiva do Ki-67 em 13,84\% em TOQC não associado à SCNBC. D. Marcação positiva do Ki-67 em 23,32\% em TOQC à

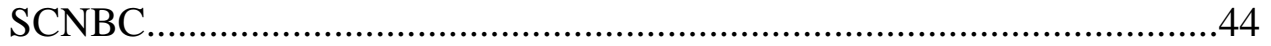

Figura 5.6 - Padrão de marcação do tumor primário e recidivado p53 do mesmo paciente (IQ). A. Marcação em 78,09\% em TOQC primário. B. Marcação em $48,28 \%$ em TOQC recidivado 


\section{LISTA DE TABELAS}

Tabela 4.1 - Quantidade de pacientes e TOQCs por Grupo.........................................26

Tabela 4.2 - Número total de TOQCs para cada marcador e suas respectivas informações

Tabela 5.1 - Faixa etária distribuída em classes de 10 anos .32

Tabela 5.2 - Variáveis clínicas dos 74 pacientes com TOQCs nos Grupos 1 e 2 .........34

Tabela 5.3 - Variáveis clínicas dos 92 TOQCs nos Grupos 1 e 2.................................36

Tabela 5.4 - Manifestações clínicas dos 14 pacientes portadores da SCNBC. 39

Tabela 5.5 - Padrão de marcação dos anticorpos CQ 14, CQ 17, CQ 19, p53, Ki-67 para os TOQCs dos Grupos 1 e 2 .......................................................42

Tabela 5.6 - Correlação entre a positividade de células e intensidade da marcação para o p53 nos Grupos 1 e 2

Tabela 5.7 - Padrão de marcação dos anticorpos CQ 14, CQ 17, CQ 19, p53 e Ki-67 para os TOQCs Primários e Recidivados.

Tabela 5.8 - Padrão de marcação do TOQC para a CQ 14, CQ 17 e p53 para lesões primárias e recidivadas. 


\section{LISTA DE ABREVIATURAS E SIGLAS}

$\begin{array}{ll}\text { CBC } & \text { carcinoma basocelular } \\ \text { COO } & \text { cisto odontogênico ortoqueratinizado } \\ \text { COX-2 } & \text { cicloxigenase-2 } \\ \text { CQ } & \text { citoqueratina } \\ \text { g } & \text { grama } \\ \text { GLI } & \text { glioma-associated oncogene } \\ \text { HH } & \text { hedgehog } \\ \text { ml } & \text { mililitro } \\ \text { mm } & \text { milímetro } \\ \text { OMS } & \text { organização mundial da saúde } \\ \text { PTCH } & \text { patched } \\ \text { QO } & \text { queratocisto odontogênico } \\ \text { SCNBC } & \text { síndrome do carcinoma basocelular nevóide } \\ \text { SHH } & \text { sonic hedgehog } \\ \text { SMO } & \text { smoothened } \\ \text { SUFU } & \text { supressor of fused } \\ \text { TO } & \text { tumor odontogênico } \\ \text { TOQC } & \text { tumor odontogênico queratocístico } \\ 9 q 22.3 & \text { braço longo do cromossomo 9 locus } 22.3\end{array}$




\section{SUMÁRIO}

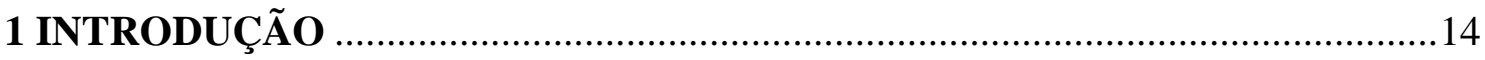

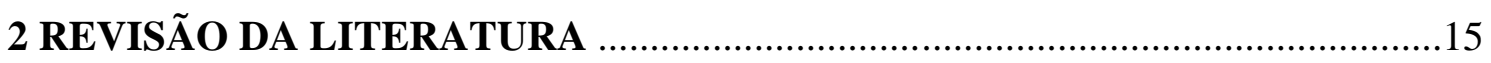

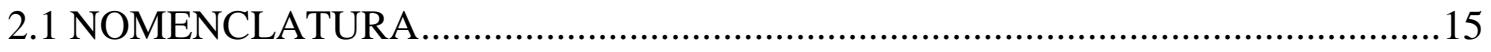

2.2 CARACTERÍSTICAS CLÍNICAS E RADIOGRÁFICAS .......................................15

2.3 CARACTERÍSTICAS HISTOPATOLÓGICAS ………………………………......16

2.4 CARACTERÍSTICAS IMUNOISTOQUÍMICAS …………………………........17

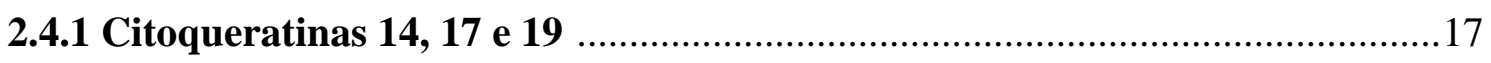

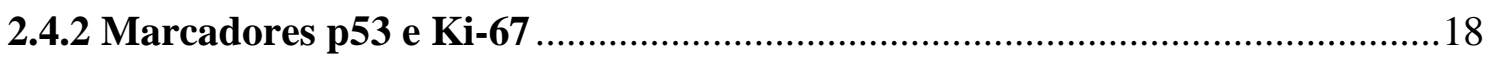

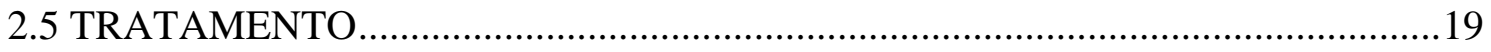

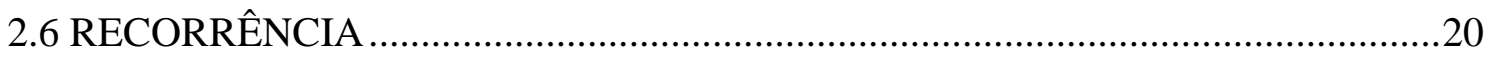

2.7 SÍNDROME DO CARCINOMA NEVÓIDE BASOCELULAR ……………….......21

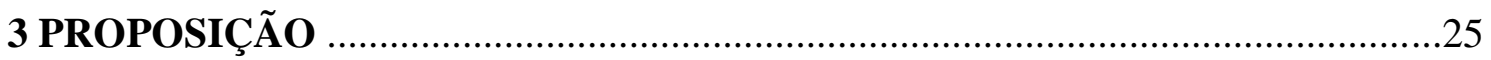

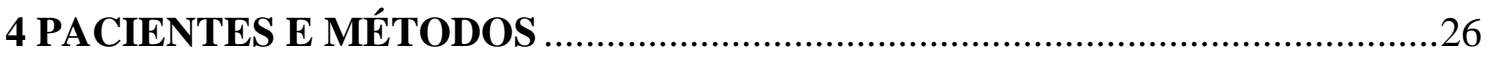

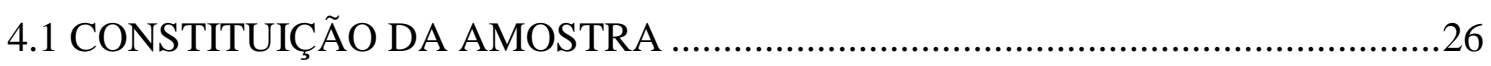

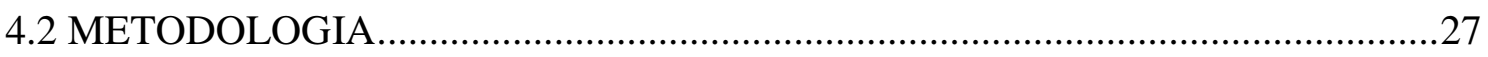

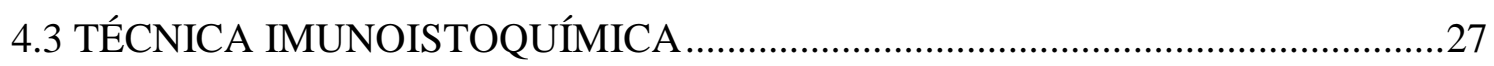

4.4 ANÁLISE DAS REAÇÕES IMUNOISTOQUÍMICAS............................................30

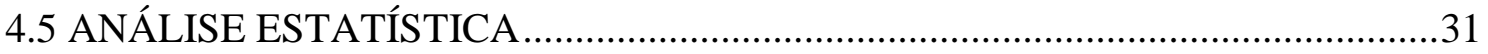

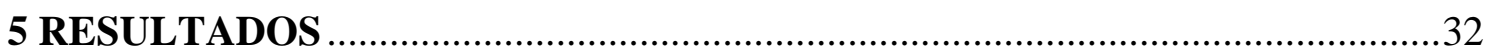

5.1 DADOS DEMOGRÁFICOS E CLÍNICOS DOS 74 PACIENTES ...........................32

5.2 INFORMAÇÕES DOS 92 TOQCs PRIMÁRIOS .....................................................35

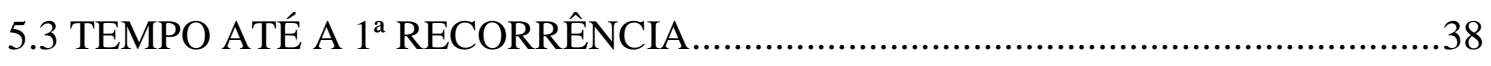

5.4 TEMPO DO SEGUIMENTO DOS 74 PACIENTES ………………….................38

5.5 PACIENTES PORTADORES DA SCNBC ……………...................................

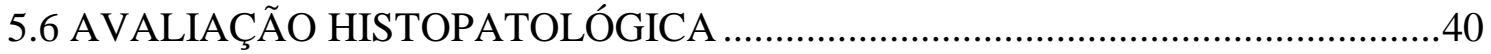

5.7 AVALIAÇÃO IMUNOISTOQUÍMICA ……………………………………......

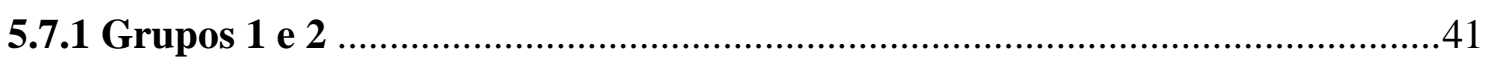

5.7.2 Grupos P (Primários) e R (Recidivados)..........................................................4

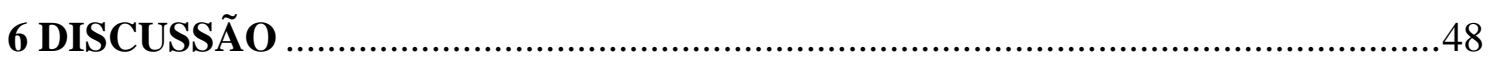


7 CONCLUSÕES

.55

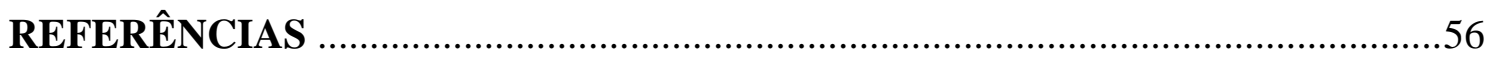

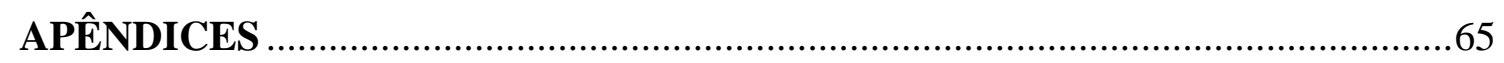

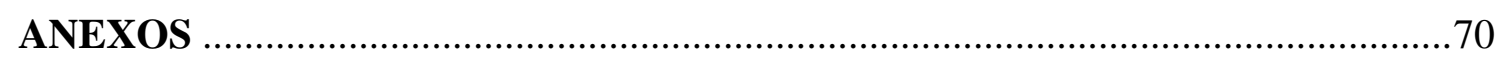




\section{INTRODUÇÃO}

Os Tumores Odontogênicos (TO) são lesões incomuns e sua origem está associada ao órgão dental ou aos seus remanescentes, podendo se desenvolver a partir do epitélio odontogênico, do ectomesênquima ou de ambos. O comportamento clínico dessas lesões varia consideravelmente. Alguns apresentam potencial de crescimento limitado, enquanto outros possuem características de uma neoplasia (Mosqueda-Taylor et al., 1997).

Há alguns anos, o queratocisto odontogênico (QO) fazia parte da entidade dos cistos odontogênicos. No entanto, recentemente, foi reclassificado pela Organização Mundial da Saúde (OMS) como tumor benigno recebendo a atual denominação de Tumor Odontogênico Queratocístico (TOQC). Essa nova nomenclatura foi proposta devido sua natureza neoplásica, não encontrada em outros cistos odontogênicos. O TOQC é uma lesão que se origina do epitélio odontogênico, sem participação do ectomesênquima. Apresenta-se exclusivamente nos ossos gnáticos, com alto potencial de agressividade local. Pode estar associado à Síndrome do Carcinoma Nevóide Basocelular (SCNBC), que se caracteriza por apresentar inúmeras alterações de desenvolvimento, múltiplos carcinomas basocelulares (CBCs), além de anormalidades esqueléticas. Entre 65 a 100\% dos pacientes com a SCNBC podem apresentar múltiplos TOQCs (Barnes et al., 2005; Amezaga et al., 2008).

O comportamento clínico dos TOQCs é incerto, principalmente das lesões associadas à SCNBC. Atualmente, o contínuo desenvolvimento de pesquisas clínicas e laboratoriais nos permite obter maiores esclarecimentos quanto à patogênese deste tumor e, ainda, avaliar e correlacionar dados clínicos com os aspectos histopatológicos e imunoistoquímicos.

Assim, o objetivo do presente estudo é investigar o comportamento clínico dos TOQCs associados e não associados à SCNBC, assim como avaliar dados da análise imunoistoquímica. 


\section{REVISÃO DE LITERATURA}

\subsection{NOMENCLATURA}

Primeiramente descrito por Philipsen em 1956, o queratocisto odontogênico (QO) foi classificado como cisto de desenvolvimento. No entanto, em 2005, foi reclassificado pela Organização Mundial da Saúde (OMS) como tumor benigno, recebendo a denominação de Tumor Odontogênico Queratocístico (TOQC). Muitos fatores contribuíram para esta nova classificação como seu comportamento clínico, as altas taxas de recorrência e associação com a SCNBC (Barnes et al., 2005).

\subsection{CARACTERÍSTICAS CLÍNICAS E RADIOGRÁFICAS}

Os TOQCs possuem predileção pelo sexo masculino com proporção homem:mulher que varia de 1.42:1 a 2:1. O tumor pode acometer indivíduos em todas as idades, porém a maior incidência ocorre entre $3^{\mathrm{a}}$ e $4^{\mathrm{a}}$ décadas de vida, com idade média em torno de 30 anos de idade. Em relação à localização são encontrados em qualquer região dos maxilares. No entanto, a mandíbula é mais comumente afetada, principalmente as regiões de ângulo e ramo. Normalmente são assintomáticos e estes são detectados incidentalmente em radiografias de rotina. Quando são sintomáticos, as queixas mais comuns são inchaço, dor ou ambos. Outras manifestações como drenagem purulenta e parestesia podem ser observados em lesões mais extensas (Woolgar et al., 1987; Myoung et al., 2001; Zhao et al., 2002; Boffano et al., 2010; González-Alva et al., 2008).

Radiograficamente, os TOQCs se apresentam como imagem radiolúcida de forma circular ou ovóide, podendo ser uniloculares ou multiloculares. As margens da lesão são escleróticas e geralmente, bem definidas. Quando associado aos dentes pode provocar deslocamento e/ou afastamento, mas raramente reabsorção radicular (Brannon, 1976; Bataineh; al Qudah, 1998; Chirapathomsakul et al., 2006). 


\subsection{CARACTERÍSTICAS HISTOPATOLÓGICAS}

A análise histopatológica revela que a cápsula cística dos TOQCs é revestida por epitélio estratificado paraqueratinizado com espessura delgada e regular. O número de camadas epiteliais varia de 5 a 8 , com interface plana entre o epitélio e a cápsula cística. É comum haver destacamento epitelial do tecido de suporte devido degradação do colágeno mediada pelas metaloproteinases (Donoff et al., 1972; Philipsen et al., 1976).

A camada basal é bem definida, composta por células colunares ou cúbicas, frequentemente dispostas em paliçada. Os núcleos das células basais têm tendência a se orientarem no sentido oposto ao da membrana basal e geralmente é basofílico. Nas camadas suprabasais pode haver sinais de mitoses e raramente apresentar displasia epitelial. A arquitetura epitelial do TOQC pode variar caso haja intenso infiltrado inflamatório podendo formar projeções com perda da característica da camada basal em paliçada.

As camadas de paraqueratina se apresentam com superfície corrugada e queratina pode estar presente na cavidade cística. Focos de ortoqueratinização, também, podem ser observados (Jordan, 2003). Devido à semelhança histopatológica, o cisto odontogênico ortoqueratinizado (COO) era caracterizado como uma variante do TOQC. No entanto, baseando-se no comportamento clínico, Wright (1981), sugeriu a distinção entre as duas lesões. Em concordância, alguns estudos também mostraram diferenças entre características histopatológicas e perfil imunoistoquímico destas lesões. Atualmente, o COO é considerado como uma entidade distinta (Crowley et al., 1992; Vuahula et al., 1993; Barnes et al., 2005).

A cápsula cística dos TOQCs é delgada, composta por tecido fibroso rico em mucopolissacarídeos, que pode ou não apresentar inflamação. Ilhas de células epiteliais odontogênicas podem estar presentes na cápsula em 5-60\% dos casos e microcistos satélites em 6,1-60\% (Li et al., 1998; Myoung et al., 2001; Thosaporn et al., 2004; Barnes et al., 2005; Kuroyanagi et al., 2009; Aragaki et al., 2010). 


\subsection{CARACTERÍSTICAS IMUNOISTOQUÍMICAS}

\subsubsection{Citoqueratinas 14, 17 e 19}

As citoqueratinas $(\mathrm{CQ})$ são proteínas importantes para o reconhecimento de tumores de origem epitelial e podem caracterizar o grau de maturação do tecido. Pertencem a um grupo de filamentos intermediários presentes no citoesqueleto celular e atualmente são classificadas em duas subfamílias: ácida (tipo I) e básica (tipo II). A subfamília ácida é composta pelas CQs 9, 10, 12-28, 31-40 e a subfamília básica pelas CQs 1-8, 71-86 (Moll et al., 2008).

Cada tecido epitelial possui um perfil de expressão de CQ que é útil para sua identificação e caracterização imunofenotípica. Em cistos e tumores odontogênicos, a imunoexpressão das CQs pode proporcionar um diagnóstico preciso e auxilia a elucidar a patogênese dos mesmos, inclusive dos TOQCs (Shear, 2002a).

A CQ 14 é o principal filamento intermediário observado na lâmina dentária, epitélio reduzido do esmalte e em quase todas as células do órgão do esmalte e tumores odontogênicos. A CQ 17 é comumente expressa em células basais e mioepiteliais de epitélios complexos e epitélios de transição. A CQ 19 é encontrada em epitélios simples e ocasionalmente em células basais de epitélios não queratinizados (Crivelini et al., 2003, Stoll et al., 2005).

Meara et al. (2000), estudaram as CQs 13, 17, 18 e AE1/AE3 em cistos e tumores odontogênicos e verificaram resultados relevantes com a imunoexpressão da CQ 17, sendo esta mais intensa e uniforme em TOQCs associados à SCNBC se comparados aos TOQCs não associados à síndrome. Os autores puderam concluir que a CQ 17 pode funcionar como uma ferramenta adicional para diferenciar os dois grupos de TOQCs. Contudo, não foram observadas diferenças relevantes nas outras CQs.

Neste mesmo sentido, Stoll et al. (2005) avaliaram os diferentes padrões de expressão das CQs $(5 / 6,7,10,13,17,19$ e 20) como ferramenta adicional para caracterizar cistos radiculares, dentígeros e TOQCs. Somente as CQs 17 e 19 apresentaram expressões relevantes. A CQ 17, diferentemente dos outros cistos, mostrou intensa positividade em todo o epitélio dos TOQCs, e CQ 19 se mostrou negativa somente nos TOQCs. Santos et al. (2009) estudaram a expressão das CQs 7, 8, 10,13, 14, 18 e 19 com objetivo de comparar o estado de 
maturação epitelial em TOQCs primários, recorrentes e associados à SCNBC. Somente as CQs 13, 14, 18 e 19 foram expressas, no entanto, não foram observadas diferenças entre os grupos estudados.

\subsubsection{Marcadores p53 e Ki-67}

Em relação aos TOQCs, muitos trabalhos têm mostrado sua agressividade e potencial de recidivas através da imunoexpressão de proteínas específicas (Gurgel et al., 2008). Ki-67 é uma proteína nuclear, utilizada como marcador de proliferação celular em diversas neoplasias.

É expressa em todas as fases do ciclo celular ativo (G1, S, G2 e M) e alcança um pico nas fases G2 e M. Rapidamente se degrada após a mitose com meia-vida de uma hora ou menos (Scholzen; Gerdes, 2000). A proteína p53, codificada pelo gene supressor de tumor TP53, é utilizada para detecção de neoplasias malignas e progressão tumoral. Em células normais, possui pequeno tempo de meia-vida, já na forma mutada, o tempo de meia vida é prolongado, sendo passível sua detecção pelo método imunoistoquímico. Apresenta função de impedir a divisão celular frente a uma agressão, evitando a replicação de células danificadas. A inativação do TP53 permite a replicação de células mutadas que eventualmente promoverá o desenvolvimento tumoral (De laurenzi; Melino, 2000; Shear 2002b).

A imunoexpressão da proteína p53, bem como do Ki-67 é maior nos TOQCs em comparação a outros cistos odontogênicos, mais particularmente em TOQCs associados à SCNBC (Li et al. 1995; Shear, 2002b, Mateus et al. 2008; Ayoub et al. 2011). Ogden et al. (1992) investigaram a expressão da p53 em TOQCs, cistos radiculares e dentígeros e observaram positividade somente em TOQCs. A positividade foi identificada nas células da camada basal. Ainda, estes autores verificaram que a intensidade da marcação é inferior aos tumores malignos da cavidade oral. Li et al. (1995) verificaram a expressão da proteína ki-67 em três grupos de TOQCs: não recorrentes, recorrentes e associados à SCNBC. Não foi observada diferença na expressão entre os grupos não recorrentes e recorrentes, no entanto, no grupo de TOQCs associados à SCBNC, a positividade foi significantemente maior. Em outro estudo, Li et al. (1996) observaram a imunoexpressão da proteína p53 nos diferentes grupos de TOQCs, cistos radiculares e dentígeros. A imunoexpressão foi maior nos TOQCs não recorrentes em relação aos cistos dentígeros e radiculares, porém não encontraram diferenças entre os grupos de TOQCs. Neste mesmo estudo, não foram observadas mutações no gene 
TP53 em pacientes que desenvolveram TOQCs sugerindo, então, que a expressão encontrada nestes tumores se deve ao acúmulo da proteína p53 do tipo selvagem.

Lombardi et al. (1995) também estudaram os três grupos de TOQCs: primários, recorrentes e associados à síndrome, perante a expressão da proteína p53. Todas as lesões tiveram o mesmo padrão de marcação e a intensidade foi considerada variável e fraca se comparadas aos casos de lesões orais com displasia e carcinomas epidermóides, usados como controle. Não foram observadas diferenças na expressão da p53 entre os grupos de TOQCs estudados.

Gurgel et al. (2008) mostraram aumento da proliferação celular através da proteína p53 e Ki-67 preferencialmente na camada supra-basal do epitélio em 37 TOQCs, no entanto não foi observado diferenças na expressão entre os grupos de TOQCs associados à síndrome, não associados à síndrome e lesões primárias e recorrentes. Verificou-se também a expressão da proteína p63, codificada pelo gene P63 (homólogo ao P53) e constataram aumento da expressão nas camadas basal e supra-basal. Os autores concluíram que o comportamento biológico dos TOQCs pode estar relacionado à proliferação celular da camada supra-basal do epitélio sugerindo sua origem tumoral.

Mendes et al. (2011) avaliaram a imunoexpressão da cicloxigenase-2 (COX-2), p53 e ki-67 em 20 casos de TOQCs e buscaram associar a expressão destes marcadores. Contudo, não verificaram resultados estatisticamente significantes na associação da expressão entre os grupos esporádicos/sindrômicos, primários/recorrentes.

\subsection{TRATAMENTO}

As modalidades terapêuticas para o tratamento dos TOQCs são bastante discutidas na literatura devido aos elevados índices de recorrências relatados. Variam desde procedimentos conservadores como marsupialização, descompressão e enucleação cística a procedimentos agressivos como ressecções marginais e radicais. A vantagem das técnicas mais conservadoras é a preservação de estruturas anatômicas e menor taxa de morbidade.

Com o intuito de diminuir o índice de recidivas, foram propostas terapias adjuvantes associadas à enucleação como ostectomia periférica, crioterapia e solução de carnoy. A ostectomia periférica ou curetagem óssea consiste no desgaste ou raspagem da loja óssea com instrumental rotatório ou cureta. A crioterapia promove morte celular nas margens ósseas por 
congelamento com temperaturas que devem ser inferiores a $-20^{\circ} \mathrm{C}$. E a aplicação da solução de Carnoy nas paredes ósseas promove necrose química com margem de segurança de até 1,5 $\mathrm{mm}$. Cada $10 \mathrm{ml}$ de solução de carnoy contém $6 \mathrm{ml}$ de álcool absoluto, $3 \mathrm{ml}$ de clorofórmio e 1 $\mathrm{ml}$ de ácido glacial acético, associados a $1 \mathrm{~g}$ de cloreto férrico (Voorsmit et al., 1981; Pogrel 1993, Schmidt e Pogrel 2001; Zhao et al., 2002; Chirapathomsakul et al., 2006).

As modalidades de tratamento mostram índices de recidiva variados. Tonietto et al. (2011) realizaram enucleação cística associada à aplicação de nitrogênico líquido em 9 TOQCs, não observando recidivas durante 9 anos de acompanhamento pós cirúrgico. Ao avaliar diferentes modalidade de tratamento, Zhao et al. (2002) observaram recorrências em 17,79\% de 163 TOQCs tratados somente por enucleação cística, 6,7\% em 29 pacientes tratados por enucleação associada à aplicação de solução de carnoy. Não foram observadas recorrências em 11 casos em que foram realizados marsupialização associada à posterior enucleação e em 52 casos que realizaram ressecção. O tempo de acompanhamento neste estudo variou de 3 a 29 anos. Zecha et al. (2010) demonstraram índice de recorrência de 20,7\% em 58 pacientes tratados com enucleação e Boffano et al. (2010) observaram recorrências de $11,9 \%$ dos 261 tumores tratados por enucleação e curetagem.

\subsection{RECORRÊNCIA}

O TOQC é considerado como um dos tumores odontogênicos mais agressivos, principalmente por apresentar altas taxas de recorrência e tendência a invadir tecidos adjacentes. A recorrência pode ser justificada pela alta atividade mitótica epitelial, cistos satélites, restos epiteliais na cápsula cística e epitélio mais calibroso do que encontrado em outros cistos odontogênicos (Lo muzio et al., 1999; Myoung et al., 2001; Manfredi et al., 2004).

A literatura mostra altas discrepâncias quanto ao índice de recorrências que pode variar de 0 a 100\% (Shear, 2002c; Kuroyanagi et al., 2009). Isto pode ser justificado devido às variações no período de acompanhamento, técnica cirúrgica empregada, localização e tamanho do tumor, presença ou ausência de infecção, associação com dentes, envolvimento da mucosa, número de casos incorporados nos estudos (Bataineh; al Qudah, 1998, Hyun et al., 2009; Kuroyanagi et al., 2009). A maioria dos casos de TOQC apresenta recorrências nos primeiros 5 a 7 anos após o tratamento. No entanto, existem relatos na literatura de 
recorrências após 9 anos ou mais. Estes achados enfatizam a importância de um longo período de acompanhamento no planejamento terapêutico (Brannon, 1976; Meara et al., 1998; Lam; Chan, 2000; Stoelinga et al., 2001; Morgan et al., 2005).

\subsection{SÍNDROME DO CARCINOMA NEVÓIDE BASOCELULAR (SCNBC)}

Também conhecida como Síndrome de Gorlin, a SCNBC é uma condição hereditária transmitida por um cromossomo autossômico dominante, com alta penetrância e expressividade variável. É causada por mutações no gene supressor de tumor Patched $(P T C H)$, localizado no cromossomo 9q22.3. A prevalência desta síndrome é estimada em 1/57.000 a 1/256.000 (Farndon et al., 1992; Evans et al., 1991; Shanley et al., 1994; Lo Muzio et al., 1999; Ahn et al., 2004), podendo acometer igualmente os sexos e se manifestar na primeira, segunda ou terceira décadas de vida (Evans et al., 1991; Kimonis et al., 1997).

$\mathrm{O}$ gene $P T C H$ codifica a proteína transmembrana Ptch, atua na cascata de sinalização da proteína Sonic hedgehog (Shh) e está associada ao desenvolvimento de diversos tecidos, incluindo os dentes (Barreto et al., 2000). A proteína Ptch, ao ligar-se à Shh, libera a proteína transmembrana Smoothened (Smo) que se encontra inibida. A proteína Smo ativada, por sua vez, altera o destino da proteína citoplasmática Glioma associated oncogene (Gli). As proteínas Gli1 e Gli2 migram para o núcleo celular, onde servem como um ativador dos genes alvo (SHH, PTCH, GLI), enquanto que Gli3 age suprimindo. Supressor de proteínas fused (Sufu) também tem importante papel na patogênese da SCNBC ao ligar-se à proteína Gli no citoplasma e no núcleo prevenindo esta de ativar os genes alvo desta cascata (Wicking et al.,1999, Evangelista et al., 2006) (Figura 2.1). 

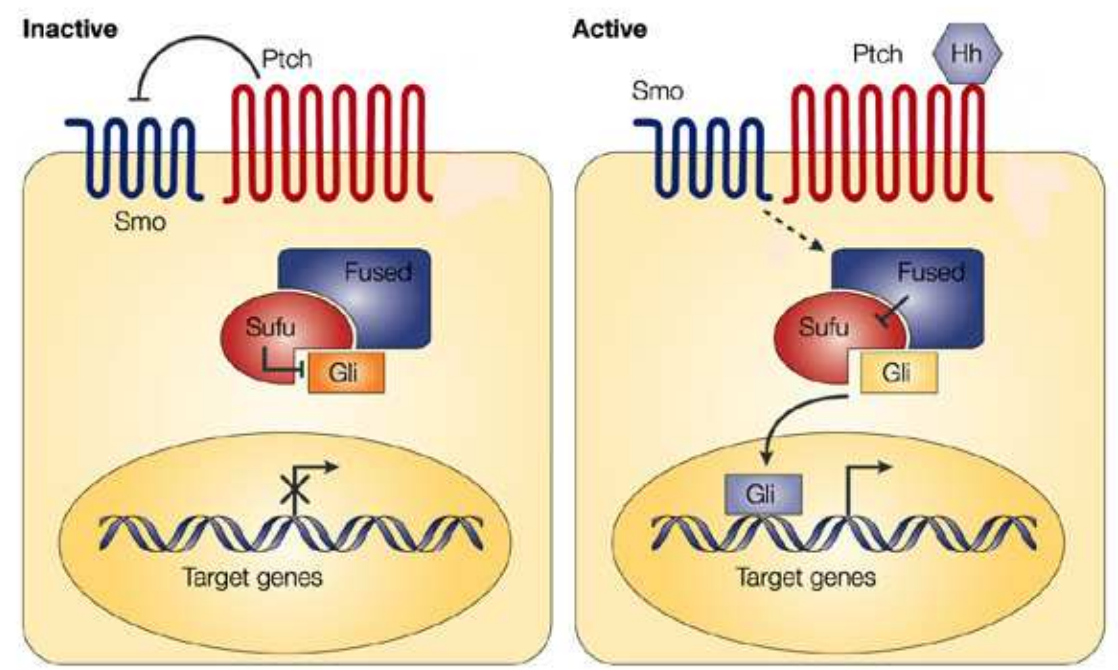

Figura 2.1: Via de sinalização do HH. Ptch está ligada a Smo e os genes alvos estão inativos. Quando ocorre a ligação da proteína Shh à Ptch, Smo é liberada permitindo a transmissão do sinal e Gli ativa a transcrição dos genes alvo. (Adaptado de Pasca di Magliano MP, Hebrok M; 2003).

Foi comprovado que o desregulamento na cascata de sinalização do $S H H$ e mutações no gene PTCH contribuem para formação de carcinomas baso-celulares (CBC) esporádicos e associados à SCNBC (Zhang et al., 2001). Recentemente alguns trabalhos têm mostrado também estas alterações em TOQCs sindrômicos e esporádicos (Barreto et al., 2000, Ohki et al., 2004, Agaram et al., 2004, Sun et al., 2008).

As manifestações clínicas da SCNBC são extremamente variadas, sendo as mais comuns os carcinomas basocelulares (CBC), TOQCs, “"“pits"” palmares e/ou plantares e calcificação da foice cerebral. O critério de diagnóstico é baseado nas características mais freqüentes da síndrome, proposto inicialmente por Evans et al. (1993) e posteriormente foi modificado por Kimonis et al. (1997). Atualmente, Evans e Frarndon (2010) propuseram novos critérios devido à viabilidade de testes moleculares com os quais ampliaram o espectro fenotípico da sínsrome. O critério de diagnóstico para a síndrome requer a presença de dois critérios maiores ou um critério maior e dois critérios menores como mostrado abaixo (Kimonis et al., 1997).

- Critérios maiores: 1. Mais de 2 CBCs ou 1 abaixo dos 20 anos de idade, 2. TOQC, 3. 3 ou mais “" "pits"” palmares e/ou plantares, 4. Calcificação da foice cerebral, 5. Costelas bífidas, fusionadas ou alargadas, 6. Parente de primeiro grau com SCNBC. 
- Critérios menores: 1. Macrocefalia, 2. Malformações congênitas: fenda palatina ou labial, bossa frontal, "coarse face", hipertelorismo, 3. Outras anormalidades esqueléticas: deformidade de Sprengel, sindactilia, 4. Anormalidades radiológicas: calcificação da sela turcica, anomalias nas vértebras, defeitos de nascença nas mãos ou pés, 5. Fibromas de ovário, 6. Meduloblastoma.

Abaixo seguem as possíveis manifestações clínicas encontradas em pacientes portadores da SCNBC (Lo Muzio et al., 2008):

- Pele: "pits" palmo-plantares (30-85\%), múltiplos CBCs (30-90\%), cistos dermóides (50\%), - Sistema Estomatognático: dentes ectópicos, dentes heterotópicos, dentes impactados, agenesia dental, maloclusão, fibrossarcoma, ameloblastoma, mixoma odontogênico, carcinoma de células fusiformes, fendas palatinas ou labiais (5\%), carcinoma de células escamosas, mordida aberta, pseudocistos idiopáticos, hiperplasia do processo coronóide,

- Sistema Esquelético e Muscular: Anomalias congênitas: costelas bífidas, fusionadas, alargadas ou ausentes (30-60\%), vértebras fusionadas ou bífidas, escoliose, bossa frontal (25\%), bossa temporal e parietal, polidactilia, sindactilia, quarto metacarpo curto, ombro de Sprengel, cistos ósseos,

- Sistema Gênito-urinário: Homens: hipogonadismo (5-10\%), criptorquidia. Mulheres: calcificações no ovário, cistos no ovário (25-50\%), fibroma no ovário,

- Sistema Respiratório: cistos broncogênicos, doença da membrana hialina,

- Sistema Gastro-enteral: cistos linfomesentéricos, pólipos gástricos,

- Sistema Nervoso Central: calcificações ectópicas: calcificação da foice cerebral (70-85\%), tentorium cerebella (20-40\%), calcificações meníngeas, calcificação da sela túrcica (25\%), meningioma, meduloblastoma, glioblastoma multiforme, atraso mental moderado (5\%), epilepsia, hidrocefalia congênita, corea de huntington,

- Sistema Ocular: catarata, coloboma, microftalmia, chalazions, estrabismo, nistagmo rotatório, exoftalmia, hipertelorismo (70\%), cegueira congênita,

- Sistema Cardio-vascular: fibroma cardíaco, ausência da artéria carótida interna,

- Sistema Auditivo: otosclerose, perda do conduto auditivo, orelhas anguladas.

O diagnóstico da SCNBC é baseado na história familiar, exame intra-oral, exame da pele, radiografias de tórax e crânio, radiografia panorâmica dos maxilares, ressonância magnética do cérebro e ultrasonografia pélvica em mulheres (Bitar et al., 2002).

Cerca de 65 a 100\% dos pacientes com a síndrome desenvolvem TOQCs (Amezaga et al., 2008). A maior incidência destes tumores associados à síndrome ocorre entre a $1^{\mathrm{a}} \mathrm{e} 2^{\mathrm{a}}$ décadas de vida. A localização mais comumente afetada é a região posterior de mandíbula, 
assim como os TOQCs não associados à síndrome (Ahn et al., 2004). Nos pacientes portadores de SCNBC os TOQCs geralmente são múltiplos e tem maior tendência à recorrência. O aparecimento de novos tumores é comum até os 30 anos de idade e podem variar de 1 a 30 (Lo Muzio et al., 1999; Lo Muzio, 2008).

Na literatura, têm sido relatadas algumas diferenças entre os TOQCs associados à SCNBC e TOQCs esporádicos. Microscopicamente, os TOQCs sindrômicos tendem a ter mais cistos-satélites, ilhas sólidas de proliferação epitelial e restos de epitélio odontogênico na cápsula fibrosa do que os não sindrômicos. Os TOQCs associados à síndrome têm maior potencial de crescimento, capacidade de infiltração e tendência a desenvolver mais recorrências se comparados aos TOQCs esporádicos. Como já mencionado anteriomente as análises imunoistoquímicas mostram que a taxa de proliferação celular nos TOQCs associados à síndrome é maior (Li et al., 1995, Shear 2002b).

A correlação das características clínicas dos TOQCs e expressão imunoistoquímica são amplamente estudadas, porém poucos trabalhos são relevantes e a maioria possui casuística reduzida. Desta forma, mais estudos são necessários para melhor entendimento da patogênese e do comportamento clínico dos TOQCs esporádicos e associados à SCNBC. 


\section{PROPOSIÇÃO}

Os objetivos deste estudo foram:

- Avaliar e correlacionar os achados clínicos e expressão imunoistoquímica dos marcadores de prognóstico (p53 e Ki-67) e histogênese tumoral CQ 14, 17 e 19 em TOQCs associados ou não à SCNBC. 


\section{PACIENTES E MÉTODOS}

\subsection{CONSTITUIÇÃO DA AMOSTRA}

Inicialmente foi realizado levantamento de 587 cistos odontogênicos e não odontogênicos através dos resultados de anátomo-patológicos do Departamento de Anatomia Patológica do Hospital AC Camargo, entre o período de 1970 e 2009. Todas as lâminas foram revisadas pelos dois patologistas colaboradores do estudo e os casos de TOQCs foram classificados segundo os critérios da Organização Mundial da Saúde (Barnes et al, 2005). Nos casos com lâminas ausentes ou em má qualidade, novos cortes com $5 \mu \mathrm{m}$ de espessura foram realizados e corados em Hematoxilina e Eosina (HE). Contudo, 51 (11\%) casos dos 587 não apresentavam material para revisão. Entre os 536 casos revisados histologicamente, 119 eram TOQCs que correspondiam a 78 pacientes.

Destes 78 pacientes selecionados para o estudo, 4 foram excluídos, um por ser externo à instituição e 3 por indisponibilidade de prontuários. Com isso, a amostra foi constituída por 74 pacientes, sendo 60 pacientes não portadores da SCNBC (Grupo 1) e 14 portadores da SCNBC (Grupo 2). Estes pacientes apresentaram um total de 115 TOQCs, sendo 92 TOQCs primários (P) e 23 TOQCs recorrentes (R) (Tabela 4.1). No Grupo 1, apenas 1 paciente apresentou 2 TOQCs, no entanto, não foi possível verificar associação à SCNBC pois o paciente já havia falecido.

Tabela 4.1: Quantidade de pacientes e TOQCs por grupo.

\begin{tabular}{|c|c|c|c|c|c|c|}
\hline \multirow[b]{2}{*}{ Grupos } & \multicolumn{2}{|c|}{ Pacientes } & \multicolumn{2}{|c|}{ TOQC-P } & \multicolumn{2}{|c|}{ TOQC-R } \\
\hline & $\mathbf{n}$ & $\%$ & $\mathbf{n}$ & $\%$ & $\mathbf{n}$ & $\%$ \\
\hline 1 & 60 & 80,82 & 61 & 65,93 & 15 & 65,22 \\
\hline 2 & 14 & 19,17 & 31 & 34,06 & 8 & 34,78 \\
\hline Total & 74 & 100 & 92 & 100 & 23 & 100 \\
\hline
\end{tabular}




\subsection{METODOLOGIA}

A pesquisa foi aprovada pelo Comitê de Ética em Pesquisa do Hospital AC Camargo, São Paulo, conforme registro 1322/09 (ANEXO A).

Trata-se de um estudo retrospectivo em que foram avaliados os prontuários dos pacientes com o diagnóstico de TOQC atendidos no Hospital AC Camargo no período informado. Os dados clínicos de 74 pacientes incluindo idade, gênero, tempo de queixa, sinais, sintomas, localização, achados radiográficos, tipo de tratamento efetuado, recorrência, associação com a síndrome SCNBC e situação clínica na última avaliação foram obtidos a partir dos prontuários médicos localizados no Serviço de Arquivo Médico (SAME) e sumarizados em fichas clínicas padronizadas para o estudo (APÊNDICE A). As características clínicas dos pacientes portadores da SCNBC foram avaliadas de acordo com os critérios de diagnóstico utilizados por Kimonis et al. (1997). A situação clínica da última informação clínica do paciente foi avaliada como: vivo sem doença, vivo com doença, óbito ou fora de acompanhamento. Foram considerados como fora de acompanhamento aqueles pacientes que não tiveram acompanhamento mínimo de 1 ano.

\subsection{TÉCNICA IMUNOISTOQUÍMICA}

Para a realização das reações imunoistoquímicas, foram selecionados os blocos em parafina das peças cirúrgicas, mais representativos de cada caso e novos cortes foram realizados. As reações imunoistoquímicas foram padronizadas para cada anticorpo para estabelecer a diluição e método de recuperação antigênica adequados. Cortes de $3 \mu \mathrm{m}$ de espessura do material incluído em parafina foram deixadas por 24 horas em estufa à $60^{\circ} \mathrm{C}$. Os cortes foram desparafinizados em xilol a $60^{\circ} \mathrm{C}$ por 20 minutos e à temperatura ambiente por 20 minutos. Em seguida foram passados em etanol nas concentrações de 100\%, 85\% e 70\%, 30 segundos cada troca. Posteriormente os cortes foram passados em água corrente e água destilada.

A recuperação antigênica foi realizada pelo calor úmido sob pressão (Solar, Rapid Express, Tramontina $\left.{ }^{\circledR}\right)$ em solução tampão Tris - EDTA pH 9.0 para o anticorpo CQ17 e solução tampão citrato $10 \mathrm{mM}$ pH 6.0 para o restante dos anticorpos (p53, ki-67, CQ14 e CQ 
19). As lâminas foram mergulhadas na solução em ebulição e a panela foi lacrada com válvula seletora de pressão no número 2 e deixadas por 4 minutos após o início da pressurização total. Para a despressurização total o vapor foi liberado e a panela deixada fechada sob água corrente. Em seguida, as lâminas foram lavadas em água corrente e água destilada.

$\mathrm{O}$ bloqueio da peroxidase endógena foi realizado com $\mathrm{H}_{2} \mathrm{O}_{2} 3 \%$ (10 volumes) com 3 trocas de 10 minutos cada e em seguida as lâminas foram lavadas em água corrente e água destilada. Posteriormente foram lavadas com solução salina tamponada com fosfatos (PBSphosphate buffered saline) $10 \mathrm{mM}$ pH7.4 por 5 minutos. As lâminas foram incubadas com os anticorpos primários diluídos em títulos pré-estabelecidos conforme tabela 1 em tampão PBS contendo albumina bovina (BSA) $1 \%$ (Sigma, A9647, EUA) e azida sódica $\left(\mathrm{NaN}_{3}\right)$ 0,1\% por 30 minutos a $37^{\circ} \mathrm{C}$ e por 18 horas a $4^{\circ} \mathrm{C}$ em câmara úmida. Em seguida as lâminas foram lavadas em tampão PBS com 3 trocas de 3 minutos cada. Para amplificação das reações, as lâminas foram incubadas por 30 minutos a $37^{\circ} \mathrm{C}$ com Post Primary Block (Novolink Polymer cod \#RE7260-k, Reino Unido) e lavadas com 3 trocas de 3 minutos cada em tampão PBS. A seguir as lâminas foram incubadas com o Novolink Polymer por 30 minutos a $37^{\circ} \mathrm{C}$ e lavadas em tampão com 3 trocas de 3 minutos cada.

A revelação das lâminas foi realizada com solução substrato: 100mg 3,3' Diaminobenzidine Tetrahydrochloride (DAB) (Sigma, D-5637, EUA); 1mL de Dimetilsulfóxido (DMSO); $1 \mathrm{~mL}$ de $\mathrm{H} 2 \mathrm{O} 2$ 6\% (água oxigenada 20 volumes); $100 \mathrm{~mL}$ de PBS; por 5 minutos a $37^{\circ} \mathrm{C}$, ao abrigo da luz. Em seguida, as lâminas foram lavadas em água corrente e destilada por 3 minutos.

A contra-coloração foi realizada com Hematoxilina de Harris por 30 segundos e lavadas em água corrente e destilada. Em seguida procedeu-se duas vezes a imersão das lâminas em água amoniacal (solução de hidróxido de amônio 0,5\%) e lavadas, em seguida, em água corrente e destilada. A desidratação das lâminas foi realizada em etanol nas concentrações $80 \%$ por 1 minuto e $100 \%$ por 1 minuto, em xilol por 2 minutos. A montagem das lâminas foi realizada em Entellan neu (Merk, 1.07961, Alemanha). Para todos os anticorpos testados foram realizadas lâminas controle da reação. Como controle positivo foi utilizado um tecido sabidamente com expressão da proteína a ser pesquisada. Para o controle negativo, foi realizada a omissão do anticorpo primário. Dos 115 blocos, 93 estavam disponíveis para a realização dos cortes para imunoistoquímica. Nas amostras em que não foi possível avaliar fragmento representativo do tumor o caso foi excluído para o determinado anticorpo (Tabela 4.2). 
Tabela 4.2. Número total de TOQCs para cada marcador e suas respectivas informações.

\begin{tabular}{lclll}
\hline Anticorpos & Total (n) & Clone & Títulos & Fabricantes/Número produto \\
\hline p53 & 90 & DO-7 & $1: 300$ & Dako, \#IR61661 \\
Ki-67 & 90 & MIB-1 & $1: 500$ & Dako, \#IR62661 \\
CQ14 & 93 & LL002 & $1: 600$ & Thermo Fisher Scientific Inc. \#MS115 \\
CQ17 & 90 & E3 & $1: 50$ & Dako, \#IR62061 \\
CQ19 & 86 & BA17 & $1: 800$ & Dako, \#RCK1 \\
\hline
\end{tabular}




\subsection{ANÁLISE DAS REAÇÕES IMUNOISTOQUÍMICAS}

A avaliação imunoistoquímica foi realizada de acordo com os grupos: TOQCs não associados à SCNBC (Grupo 1), TOQCs associados à síndrome (Grupo 2), TOQCs Primários (Grupo P) e TOQCs Recidivados (Grupo R). A leitura das reações imunoistoquímicas foi realizada por um único observador previamente treinado. Para análise dos marcadores p53 e Ki-67 foi empregado o aparelho Scanscope XT Scanner System (Aperio Technologies, Inc. Vista, CA, EUA). Desta forma, foi marcada a quantidade de 1000 células referentes à área de interesse em cada caso. A contagem foi realizada de forma automatizada pelo próprio aparelho, utilizando o algoritmo original IHC Nuclear V, que avalia especificamente marcação nuclear. Este algoritmo classifica a reação em 4 graus de intensidade, sendo consideradas positivas as marcações " $3+$ " (marcação intensa), "2+" (marcação moderada) e "1+" (marcação fraca) e como negativas aquelas indicadas como "0". Ressalta-se a intensidade foi considerada apenas para o p53. Com relação ao número de células positivas, a marcação do p53 foi dividida em 4 grupos: 1) até 10\% de células positivas, 2) de 10-25\% de células positivas, 3) de $25-50 \%$ de células positivas e 4 ) acima de $50 \%$ de células positivas. A imunorreatividade da proteína ki-67 foi avaliada através da média, mediana, e desvio padrão da porcentagem de células positivas (APÊNDICE B).

A avaliação dos marcadores CQ14, CQ17 e CQ 19 foram realizadas em microscópio óptico (Olympus). Foram avaliadas negatividade, positividade e localização da marcação. A intensidade não foi considerada. Para os casos que o padrão de marcação foi irregular e não havia padrão uniforme, foi considerada marcação inconclusiva. Para a avaliação da marcação da CQ 14 foram consideradas as localizações: B (somente camada Basal), BIS (camadas Basal, Intermediária e Superficial) e In (marcação Inconclusiva). Para a CQ 17 foram consideradas as localizações: BI (camadas Basal e Intermediária), BIS e Inconclusiva. Para a CQ 19 as localizações consideradas foram: B, BIS, IS (camadas Intermediária e Superficial) e Inconclusiva. Para os marcadores CQ14, CQ17, CQ 19 e p53 também foram considerados o padrão da marcação do TOQC $\mathrm{P}$ e R do mesmo paciente quando houve possibilidade de avaliação. 


\subsection{ANÁLISE ESTATÍSTICA}

Tanto para os dados clínicos dos pacientes quanto para os dados das lesões foram construídas as respectivas tabelas com as distribuições de freqüências.

Para verificar a existência de associação entre os dados clínicos ou os dados das lesões com a ocorrência de síndrome foi utilizado o teste Qui-Quadrado de Pearson. Nos casos em que as frequências esperadas foram menores do que cinco, foi aplicado o teste de QuiQuadrado com a correção de continuidade de Yates (Yates, 1934).

$\mathrm{O}$ teste $\mathrm{t}$ de Student foi utilizado para verificar a associação da positividade dos marcadores ki-67, p53, CQ14, CQ17 e CQ19 com a ocorrência de síndrome. Não foi possível associar os dados dos tumores ou dos marcadores com os grupos $\mathrm{P}$ e $\mathrm{R}$ pois só faz sentido associar os dados daqueles que apresentaram recidiva e estes foram em número pequeno em nossa amostra.

O nível de significância adotado foi o de $5 \%$ e as tabelas e os testes foram construídos com o auxílio do software estatístico livre R versão 12.0 (http://www.r-project.org.br). 


\section{RESULTADOS}

\subsection{DADOS DEMOGRÁFICOS E CLÍNICOS DOS 74 PACIENTES}

No grupo de pacientes não síndrome (Grupo 1) a idade variou de 9 a 74 anos de idade (média $=36$ anos e desvio padrão $=19,12)$. No grupo de pacientes com síndrome $($ Grupo 2$)$ a idade variou de 8 a 66 anos (média $=31$ anos e desvio padrão = 21,02). No Grupo 1, houve predominância de pacientes nas $3^{\mathrm{a}}$ e $4^{\mathrm{a}}$ décadas de vida e no Grupo 2, na $2^{\mathrm{a}}$ década (Tabela 3). Ao categorizar a variável idade pela mediana no dois Grupos (32 anos), observou-se uma associação estatisticamente significante $(\mathrm{p}=0.02)$ entre idade abaixo dos 32 anos e a presença de síndrome indicando que os pacientes do Grupo 2 desenvolvem TOQCs em idade mais precoce do que no Grupo 1 (Tabela 5.2).

Tabela 5.1: Faixa etária distribuída em classes de 10 anos.

\begin{tabular}{ccccc}
\hline & \multicolumn{4}{c}{ Grupos } \\
\cline { 2 - 5 } Faixa etária & \multicolumn{2}{c}{$\mathbf{1}$} & \multicolumn{2}{c}{$\mathbf{2}$} \\
\cline { 2 - 5 } & $\mathbf{n}$ & $\%$ & $\mathbf{n}$ & $\mathbf{\%}$ \\
\hline $\mathbf{0 - 9}$ & 1 & 1,67 & 1 & 7,14 \\
$\mathbf{1 0 - 1 9}$ & 9 & 15 & 5 & 35,71 \\
$\mathbf{2 0 - 2 9}$ & 14 & 23,33 & 2 & 14,29 \\
$\mathbf{3 0 - 3 9}$ & 11 & 18,33 & 4 & 28,57 \\
$\mathbf{4 0 - 4 9}$ & 8 & 13,33 & - & - \\
$\mathbf{5 0 - 5 9}$ & 6 & 10 & 1 & 7,14 \\
$\mathbf{6 0 - 6 9}$ & 8 & 13,33 & 1 & 7,14 \\
$>\mathbf{7 0}$ & 3 & 5 & - & - \\
\hline Total & 60 & 100 & 14 & 100 \\
\hline & & & &
\end{tabular}

A distribuição quanto ao sexo foi equilibrada no Grupo 1, onde 53,33\% dos pacientes eram do sexo feminino. Contudo, no Grupo 2 houve marcada predileção pelo sexo feminino (64,29\%). A maioria dos pacientes são leucodermas em ambos os Grupos (Tabela 5.2). 
A queixa principal na primeira consulta mostrou que grande parte dos pacientes do Grupo $1(46,67 \%)$ referiram inchaço e $20 \%$ não haviam queixas. Contudo, no Grupo 2, a maioria dos pacientes não havia nenhuma queixa $(57,14 \%)$ e inchaço foi referido por $35,71 \%$ dos pacientes. As queixas agrupadas na categoria "outras" foram menos encontradas e são representadas por: fístula, parestesia, lesão em mandíbula, infecção de mandíbula, tumor na face e secreção em bolsa periodontal (Tabela 5.2). O tempo de queixa principal variou de 15 dias a 180 meses no Grupo 1 (média = 16 meses e desvio padrão = 37,65). No Grupo 2 o tempo variou de 15 dias a 6 meses (média $=2$ meses e desvio padrão $=2,49$ ). Esta informação estava presente em 43 pacientes do Grupo 1 e 6 pacientes do Grupo 2.

Com relação à realização de tratamento prévio, 22 (36,67\%) pacientes do Grupo 1 e 2 $(14,29 \%)$ pacientes do Grupo 2 já haviam feito tratamento em outra Instituição. Ao exame extra-oral, no Grupo 1, 20 (33,33\%) pacientes apresentaram assimetria facial e 20 (33,33\%) não havia alterações. No Grupo 2, 7 (50\%) pacientes não apresentaram alterações. Ao exame intra-oral, no Grupo 1, 25 (41,67\%) pacientes apresentaram abaulamento das corticais. No Grupo 2, $6(42,86 \%)$ havia abaulamento e $6(42,86 \%)$ não apresentaram alterações (Tabela $5.2)$.

Sobre informações do número de TOQCs por paciente, no Grupo 1, 59 pacientes $(98,33 \%)$ pacientes apresentaram uma única lesão e um paciente apresentou 2 lesões. Nos pacientes do Grupo 2, 42,86\% apresentaram mais de um TOQC (Tabela 4). Ao categorizar a variável número de TOQCs em 1 e $>1$, houve significância estatística $(\mathrm{p}<0,001)$ mostrando que pacientes do Grupo 2 apresentam maior número de lesões (Tabela 5.2).

No Grupo 1, 41 (68,33\%) pacientes estão vivos sem doença, 3 (5\%) vivos com doença e 12 (20\%) estão fora de acompanhamento. No Grupo 2, 12 pacientes (85,71\%) estão vivos sem doença, $1(7,14 \%)$ vivo com doença e 1 (7,14\%) está sem acompanhamento (Tabela 5.2). 
Tabela 5.2: Variáveis clínicas dos 74 pacientes com TOQCs nos grupos 1 e 2.

\begin{tabular}{|c|c|c|c|c|c|}
\hline \multirow{3}{*}{ Variáveis } & \multirow{3}{*}{ Categoria } & \multicolumn{4}{|c|}{ Grupos } \\
\hline & & \multicolumn{2}{|c|}{1} & \multicolumn{2}{|r|}{2} \\
\hline & & $\mathrm{n}$ & $\%$ & $\mathrm{n}$ & $\%$ \\
\hline \multirow[t]{2}{*}{ Idade* } & $\leq 32$ anos & 27 & 45 & 11 & 78,57 \\
\hline & $>32$ anos & 33 & 55 & 3 & 21,43 \\
\hline \multirow[t]{2}{*}{ Sexo } & Feminino & 32 & 53,33 & 9 & 64,29 \\
\hline & Masculino & 28 & 46,67 & 5 & 35,71 \\
\hline \multirow[t]{2}{*}{ Etnia } & Branca & 51 & 85 & 12 & 85,71 \\
\hline & Não branca & 9 & 15 & 2 & 14,29 \\
\hline \multirow[t]{6}{*}{ Queixa principal } & Inchaço & 28 & 46,67 & 5 & 35,71 \\
\hline & Nenhuma & 12 & 20 & 8 & 57,14 \\
\hline & Dor & 7 & 11,67 & - & - \\
\hline & Inchaço+dor & 4 & 6,67 & - & - \\
\hline & Outras & 6 & 10 & - & - \\
\hline & Não informado & 3 & 5 & 1 & 7,14 \\
\hline \multirow[t]{2}{*}{ Tratamento prévio } & Não & 38 & 63,33 & 12 & 85,71 \\
\hline & Sim & 22 & 36,67 & 2 & 14,29 \\
\hline \multirow[t]{4}{*}{ Ectoscopia } & Sem alterações & 20 & 33,33 & 7 & 50 \\
\hline & Assimetria facial & 20 & 33,33 & 3 & 21,43 \\
\hline & Fístula extra-oral & 1 & 1,67 & 1 & 7,14 \\
\hline & Não Informado & 19 & 31,67 & 3 & 21,43 \\
\hline \multirow[t]{6}{*}{ Oroscopia } & Abaulamento & 25 & 41,67 & 6 & 42,86 \\
\hline & Abaulamento+fístula & 8 & 13,33 & - & - \\
\hline & Mucosa rompida & 3 & 5 & - & - \\
\hline & Fístula & 2 & 3,33 & 1 & 7,14 \\
\hline & Sem alterações & 14 & 23,33 & 6 & 42,86 \\
\hline & Não Informado & 8 & 13,33 & 1 & 7,14 \\
\hline \multirow[t]{5}{*}{$\mathrm{N}^{\circ}$ de TOQCs* } & 1 & 59 & 98,33 & 8 & 57,14 \\
\hline & 2 & 1 & 1,67 & - & - \\
\hline & 3 & - & - & 3 & 21,43 \\
\hline & 4 & - & - & 1 & 7,14 \\
\hline & 5 & - & - & 2 & 14,29 \\
\hline \multirow[t]{4}{*}{ Status do paciente } & Vivo sem doença & 41 & 68,33 & 12 & 85,71 \\
\hline & Vivo com doença & 3 & 5 & 1 & 7,14 \\
\hline & Óbito & 4 & 6,67 & - & - \\
\hline & Fora de acompanhamento & 12 & 20 & 1 & 7,14 \\
\hline Total & & 60 & 100 & 14 & 100 \\
\hline
\end{tabular}

*significância estatística 


\subsection{INFORMAÇÕES DOS 92 TOQCS PRIMÁRIOS}

Em ambos os Grupos, a mandíbula foi a localização mais acometida pelos TOQCs, correspondendo a 81,96\% e 58,06\% nos Grupos 1 e 2, respectivamente. Ao dividir os maxilares em regiões, no Grupo 1, corpo e ramo de mandíbula foi o local mais afetado com 37,7\%. Entretanto, no Grupo 2 a região posterior de maxila foi a localização mais freqüente $(38,71 \%)$. Ao associar a variável localização com os Grupos 1 e 2 foi obtida significância estatística $(\mathrm{p}=0,009)$ mostrando que pacientes com síndrome possuem menor discrepância em relação a localização dos tumores em mandíbula e maxila (Tabela 5.3).

No Grupo 1, o padrão radiográfico dos TOQCs mais predominante foi multilocular $(39,34 \%)$ (Figura 5.1) e no Grupo 2, unilocular (48,39\%) (Figura 5.2). Esta informação estava disponível em 58 TOQCs considerando os dois Grupos. Também, foi observada significância estatística $(\mathrm{p}=0.008)$. Em relação ao envolvimento das corticais ósseas pelo tumor, no Grupo 1 a maioria das lesões apresentava corticais expandidas $(21,31 \%)$ e no Grupo 2, 19,35\% das lesões havia preservação das corticais. Esta informação estava presente em 44 tumores. Avaliando a associação com dentes, a maioria das lesões, em ambos os grupos, havia associação (37,7\% no Grupo 1 e 54,17\%). Quanto à avaliação do tamanho radiográfico das lesões, esta informação estava presente em apenas 21 lesões nos dois Grupos. No Grupo 1, o tamanho radiográfico do tumor variou de 1,3 a $7 \mathrm{~cm}$ (média $=3,73 \mathrm{~cm}$ e desvio-padrão $=$ 1,47) e no Grupo 2, de 2,5 a $10 \mathrm{~cm}$ (média $=6,14 \mathrm{~cm}$ e desvio-padrão $=2,70$ ). A mediana do tamanho radiográfico foi calculada em ambos os grupos para análise estatística, no entanto não foi observada significância estatística (Tabela 5.3).

Sobre o tratamento realizado nesta Instituição, a associação de enucleação e curetagem foi a técnica mais utilizada em ambos os Grupos (55,74\% no Grupo 1 e 96,78\% no Grupo 2). Crioterapia associada à enucleação e curetagem foi realizada somente no Grupo 1, correspondendo à $32,79 \%$ dos casos. A $1^{\text {a }}$ recorrência foi observada em $21,74 \%$ considerando os dois grupos. Verificando os Grupos separadamente, a taxa de recorrência foi similar sendo $21,31 \%$ no Grupo 1 e 22,58\% no Grupo 2 (Tabela 5.3). 
Tabela 5.3: Variáveis clínicas dos 92 TOQCs nos grupos 1 e 2.

\begin{tabular}{|c|c|c|c|c|c|c|}
\hline \multirow{3}{*}{ Variáveis } & \multirow{3}{*}{\multicolumn{2}{|c|}{ Categoria }} & \multicolumn{4}{|c|}{ Grupos } \\
\hline & & & \multicolumn{2}{|c|}{1} & \multicolumn{2}{|r|}{2} \\
\hline & & & $\mathrm{n}$ & $\%$ & $\mathrm{n}$ & $\%$ \\
\hline \multirow[t]{9}{*}{ Localização* } & \multirow[t]{4}{*}{ Mandíbula } & Corpo & 15 & 24,59 & 7 & 22,58 \\
\hline & & Corpo+ramo & 23 & 37,7 & 6 & 19,35 \\
\hline & & Ramo & 11 & 18,03 & 3 & 9,68 \\
\hline & & Anterior & 1 & 1,64 & 2 & 6,45 \\
\hline & \multicolumn{2}{|l|}{ Total } & 50 & 81,96 & 18 & 58,06 \\
\hline & \multirow[t]{2}{*}{ Maxila } & Posterior & 7 & 11,48 & 12 & 38,71 \\
\hline & & Anterior & 3 & 4,92 & 1 & 3,23 \\
\hline & \multicolumn{2}{|l|}{ Total } & 10 & 16,4 & 13 & 41,94 \\
\hline & \multicolumn{2}{|c|}{ Não informado } & 1 & 1,64 & - & - \\
\hline \multirow[t]{3}{*}{ Padrão radiográfico* } & \multicolumn{2}{|l|}{ Multilocular } & 24 & 39,34 & 6 & 19,35 \\
\hline & \multicolumn{2}{|l|}{ Unilocular } & 13 & 21,31 & 15 & 48,39 \\
\hline & \multicolumn{2}{|c|}{ Não informado } & 24 & 39,34 & 10 & 32,26 \\
\hline \multirow[t]{4}{*}{ Envolvimento das corticais } & \multicolumn{2}{|l|}{ Expande } & 13 & 21,31 & 4 & 12,90 \\
\hline & \multicolumn{2}{|l|}{ Preserva } & 11 & 18,03 & 6 & 19,35 \\
\hline & \multicolumn{2}{|l|}{ Rompe } & 8 & 13,11 & 2 & 6,45 \\
\hline & \multicolumn{2}{|c|}{ Não informado } & 29 & 47,54 & 19 & 61,29 \\
\hline \multirow[t]{3}{*}{ Associação com dentes } & \multicolumn{2}{|l|}{ Sim } & 23 & 37,7 & 13 & 54,17 \\
\hline & \multicolumn{2}{|l|}{ Não } & 16 & 26,23 & 11 & 45,83 \\
\hline & \multicolumn{2}{|c|}{ Não informado } & 22 & 36,07 & 7 & 22,58 \\
\hline \multirow[t]{3}{*}{ Tamanho Radiográfico } & \multicolumn{2}{|l|}{$\leq 4 \mathrm{~cm}$} & 9 & 14,75 & 2 & 6,45 \\
\hline & \multicolumn{2}{|l|}{$>4 \mathrm{~cm}$} & 5 & 8,20 & 5 & 16,13 \\
\hline & \multicolumn{2}{|c|}{ Não informado } & 47 & 77,05 & 24 & 77,42 \\
\hline \multirow[t]{4}{*}{ Tratamento } & \multicolumn{2}{|c|}{ Enucleação e curetagem } & 34 & 55,74 & 30 & 96,78 \\
\hline & Enucleação & + curetagem + crioterapia & 20 & 32,79 & - & - \\
\hline & Ressecção & & 5 & 8,2 & - & - \\
\hline & Marsupializ & ação & 2 & 3,28 & 1 & 3,23 \\
\hline $1^{\text {a }}$ Recorrência & Não & & 48 & 78,69 & 24 & 77,42 \\
\hline & Sim & & 13 & 21,31 & 7 & 22,58 \\
\hline Total & & & 61 & 100 & 31 & 100 \\
\hline
\end{tabular}

*significância estatística 


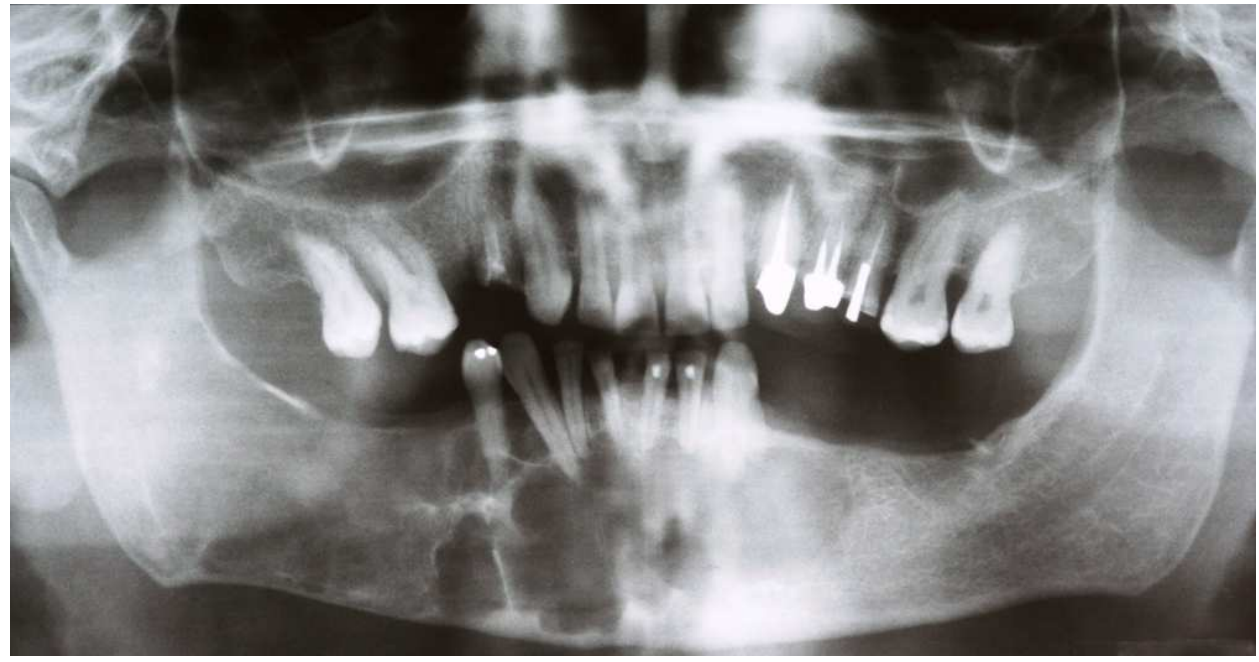

Figura 5.1: Rx panorâmico: TOQC apresentando imagem radiolúcida multilocular em região anterior de mandíbula em paciente não portador da SCNBC.

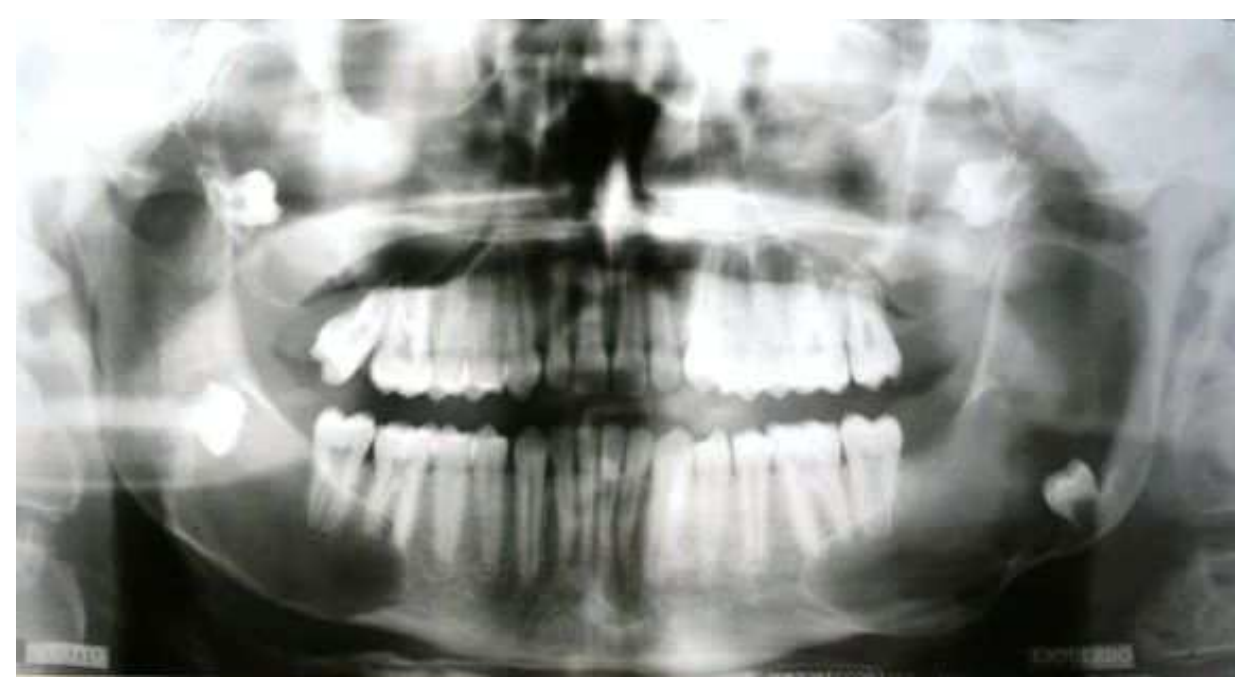

Figura 5.2: Rx panorâmico: TOQC apresentando 4 imagens radiolúcidas uniloculares, envolvendo $3^{\circ}$ molar incluso em paciente portador da SCNBC. 


\subsection{TEMPO ATÉ A $1^{\mathrm{a}}$ RECORRÊNCIA}

Dos 74 pacientes 18 apresentaram recorrência, sendo 13 no Grupo 1 e 5 no Grupo 2. Uma $2^{\mathrm{a}}$ recorrência foi observada em 1 paciente com síndrome e 3 pacientes sem síndrome. $\mathrm{O}$ tempo até a $1^{\text {a }}$ recorrência variou de 13 a 114 meses no Grupo 1 e de 9 a 149 meses no Grupo 2.

\subsection{TEMPO DO SEGUIMENTO DOS 74 PACIENTES}

O tempo de seguimento foi calculado desde a data da cirurgia até a data da última avaliação disponível. No Grupo 1 o tempo variou de 0 dia a 491 meses (média = 83,8 meses e desvio padrão $=99,71)$. No grupo 2 o tempo de acompanhamento variou de 7 dias a 295 meses (média $=78,44$ meses e desvio padrão $=90,27$ ). Um paciente apresentou complicações sistêmicas após a realização da cirurgia e foi a óbito; outro paciente compareceu para acompanhamento pós operatório após 7 dias e não retornou mais.

\subsection{PACIENTES PORTADORES DA SCNBC}

Os 14 pacientes portadores da SCNBC apresentaram 31 TOQCs primários e 8 TOQCs recorrentes. Destes pacientes, 8 apresentaram 1 lesão cada, 4 apresentaram 15 TOQCs sincrônicos, 1 paciente apresentou 3 TOQCs metacrônicos e 1 paciente teve 2 TOQCs sincrônicos e 3 metacrônicos durante o período de follow up (Tabela 5.4).

Dentre os critérios maiores, além dos TOQCs, outras manifestações clínicas foram observadas como múltiplos CBCs $(\geq 2)$ encontrados em 9 pacientes. Calcificação da foice cerebral foram observados em 6 pacientes e 5 apresentaram ““"pits"” palmares. Outras manifestações comumente encontradas neste grupo de pacientes foram nevos ( $n=9)$, cistos em pele $(n=6)$, bossa frontal proeminente $(n=5)$, miomas de ovário $(n=4)$, costelas e vértebras anormais $(n=3)$, base nasal alargada $(n=3)$, escoliose $(n=3)$, hipertelorismo $(n=2)$, parente de primeiro grau com SCNBC $(n=2)$ e prolapso da valva mitral $(n=2)$ (Tabela 5.4). 
Tabela 5.4: Manifestações clínicas dos 14 pacientes portadores da SCNBC.

\begin{tabular}{|c|c|c|c|c|c|}
\hline Paciente & Idade & TOQCs $(\mathbf{N}=31)$ & $\begin{array}{l}\text { Localização do } \\
\text { TOQC }\end{array}$ & $\begin{array}{l}\text { Recorrência } \\
\text { TOQC }(\mathrm{N}=8)\end{array}$ & Outras manifestações clínicas \\
\hline 1 & 8 & 5 & $\begin{array}{l}\text { Mand post } \mathrm{E} \\
\text { Mand post } \mathrm{D}^{*} \\
\text { Maxila ant } \\
\text { Maxila post } \mathrm{D}^{*} \\
\text { Maxila post } \mathrm{E}\end{array}$ & $\begin{array}{l}2 \\
1 \\
- \\
1 \\
-\end{array}$ & $\begin{array}{l}\text { Cisto epidermóide, costelas fusionadas, duplicação } \\
\text { endometrial, escoliose macrocefalia, nevo e prolapso da } \\
\text { valva mitral. }\end{array}$ \\
\hline 2 & 14 & 1 & Mand post $\mathrm{D}$ & - & $\begin{array}{l}\text { Baqueteamento digital, base nasal alargada, bossa frontal } \\
\text { proeminente, calcificação da foice cerebral, cistos } \\
\text { epidermóides, clinodactilia hipertelorismo, lesão } \\
\text { hipocrômica em conjuntiva, macrocefalia, nevos, pectus } \\
\text { cavitatum e "pits" palmares. }\end{array}$ \\
\hline 3 & 19 & 3 & $\begin{array}{l}\text { Mand post } \mathrm{D}+\mathrm{E}^{*} \\
\text { Maxila post } \mathrm{D}^{*} \\
\text { Maxila post } \mathrm{E}^{*}\end{array}$ & $\begin{array}{l}- \\
-\end{array}$ & $*_{2}$ \\
\hline 4 & 31 & 1 & Mand post $\mathrm{D}$ & 1 & $\begin{array}{l}\text { Cálculos renais bilaterais, cistos em mama, cisto } \\
\text { epidérmico. escoliose, hipercalciúria, lipomas em } \\
\text { abdômen, miomas, múltiplos CBCs e nevo. }\end{array}$ \\
\hline 5 & 30 & 1 & Mand post $\mathrm{E}$ & - & Calcificação da foice cerebral e múltiplos CBCs. \\
\hline 6 & 51 & 1 & Maxila post $\mathrm{D}$ & - & Carcinoma ductal de mama, múltiplos CBCs e nevos. \\
\hline 7 & 59 & 1 & Mand post $\mathrm{D}$ & 1 & $\begin{array}{l}\text { Escoliose, miomas uterinos, múltiplos CBCs, nevo e } \\
\text { osteófitos marginais em rx de coluna. }\end{array}$ \\
\hline 8 & 26 & 3 & $\begin{array}{l}\text { Mand post } \mathrm{D} \\
\text { Mand post } \mathrm{E} \\
\text { Maxila post } \mathrm{D}\end{array}$ & $\begin{array}{l}1 \\
- \\
-\end{array}$ & $\begin{array}{l}\text { Achatamento da costela, bossa frontal proeminente, } \\
\text { cistos em mama, cistos epidermóides, colescistite, } \\
\text { hipertelorismo, microcistos em pelve, mioma e múltiplos } \\
\text { CBCs. }\end{array}$ \\
\hline 9 & 35 & 1 & Maxila post $\mathrm{D}$ & 1 & $\begin{array}{l}\text { Calcificação da foice cerebral, miomas, múltiplos CBCs, } \\
\text { nevos e "pits" palmares. }\end{array}$ \\
\hline 10 & 29 & 1 & Mand corpo D & - & $\begin{array}{l}\text { Base nasal alargada, bossa frontal proeminente, } \\
\text { calcificação da foice cerebral, macrocefalia, múltiplos } \\
\text { CBCs, nevo, "pits" palmares e prognatismo. }\end{array}$ \\
\hline 11 & 14 & 4 & $\begin{array}{l}\text { Mand post } \mathrm{D}^{*} \\
\text { Mand post } \mathrm{E}^{*} \\
\text { Maxila post } \mathrm{D}^{*} \\
\text { Maxila post } \mathrm{E}^{*}\end{array}$ & $\begin{array}{l}- \\
- \\
-\end{array}$ & $\begin{array}{l}\text { Múltiplos CBCs, múltiplos nevos. parente de } 1^{\circ} \text { grau com } \\
\text { SCNBC e prolapso da valva mitral. }\end{array}$ \\
\hline 12 & 13 & 1 & Mand post $\mathrm{D}$ & - & $\begin{array}{l}\text { Bossa frontal proeminente, costelas bífidas, macrocefalia, } \\
\text { milia facial e "pits" palmares }\end{array}$ \\
\hline 13 & 34 & 5 & $\begin{array}{l}\text { Maxila post } \mathrm{D}^{*} \\
\text { Maxila post } \mathrm{E}^{*} \\
\text { Mand post } \mathrm{E}^{*} \\
\text { Mand post } \mathrm{D}^{*} \\
\text { Mand corpo } \mathrm{D}^{*}\end{array}$ & $\begin{array}{l}- \\
- \\
- \\
-\end{array}$ & $\begin{array}{l}\text { Cisto cebáceo, clinodactilia, bossa frontal proeminente, } \\
\text { base nasal alargada, macrocefalia, múltiplos CBCs, } \\
\text { palato alto, "pits" palmares e prognatismo leve. }\end{array}$ \\
\hline 14 & 17 & 3 & $\begin{array}{l}\text { Mand post } \mathrm{D}^{*} \\
\text { Mand post } \mathrm{E}^{*} \\
\text { Maxila post } \mathrm{D}^{*}\end{array}$ & $\begin{array}{l}- \\
-\end{array}$ & $\begin{array}{l}\text { Adenoma hepático, bócio em tireoide, calcificação da } \\
\text { foice cerebral, cisto renal, hipotireoidismo, } \\
\text { meduloblastoma e nevos. }\end{array}$ \\
\hline
\end{tabular}

Mand=Mandíbula, ant=anterior, post=posterior, ${ }^{*}$ TOQCs sincrônicos, ${ }_{2}$ Parente de $1^{\circ}$ grau com síndrome 


\subsection{AVALIAÇÃO HISTOPATOLÓGICA}

Em todos os casos de TOQCs, as lesões se apresentavam como cavidades císticas rodeadas por epitélio pavimentoso estratificado com espessura variando de 5-8 camadas de células. Frequentemente, a camada superficial do epitélio apresentava-se corrugada. A camada basal apresentou células cúbicas e/ou colunares em paliçada com núcleos hipercromáticos. O descolamento do tecido epitelial da cápsula cística foi observado em alguns casos. Dois casos apresentaram displasia epitelial e "brotamento" das células epiteliais na cápsula não foi um achado raro. Áreas de inflamação, cistos satélites e epitélio odontogênico na cápsula cística também foram notados (Figura 5.3).
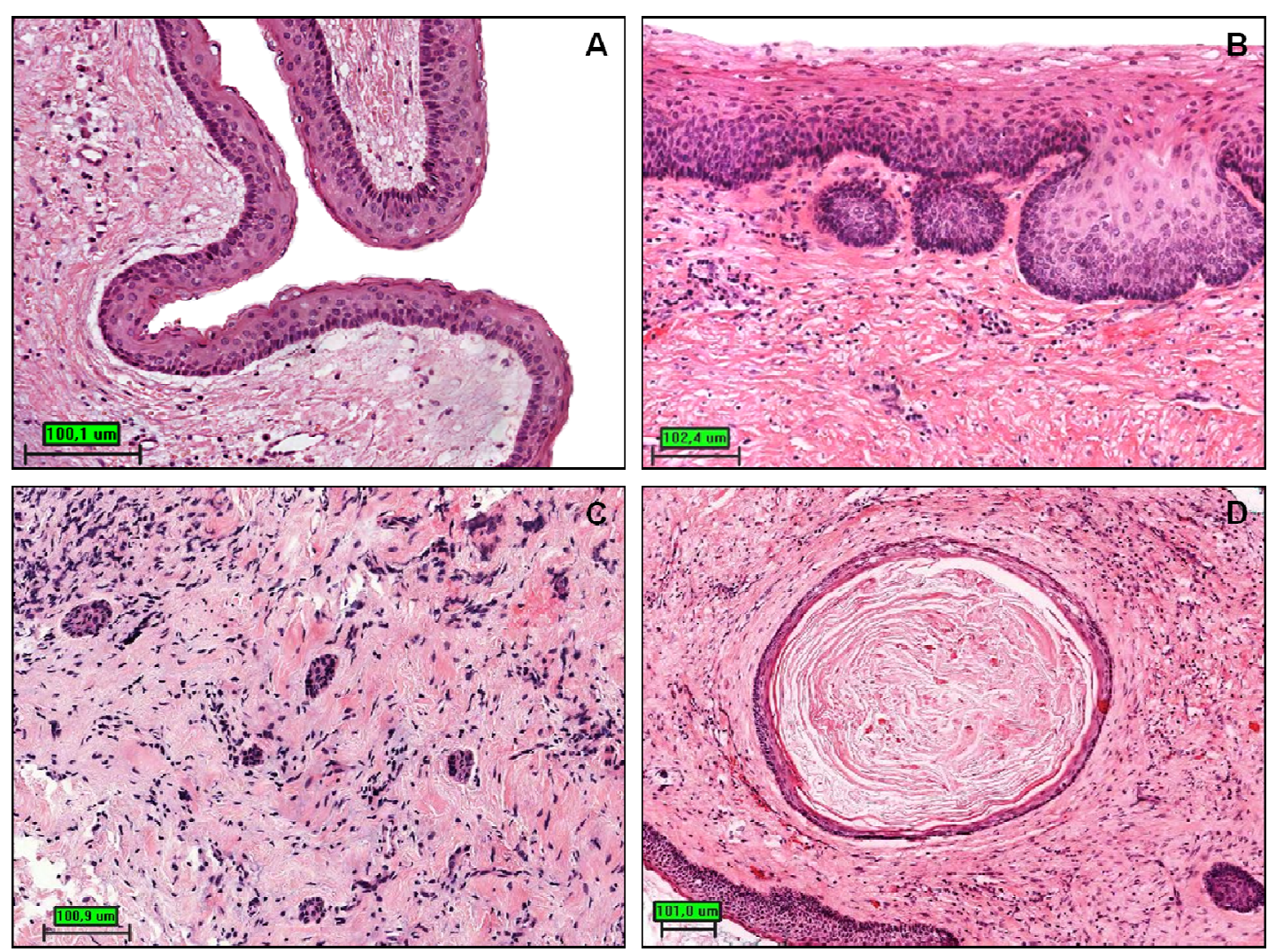

Figura 5.3: Características histopatológicas dos TOQCs (HE). A. Cápsula cística revestida por epitélio pavimentoso estratificado paraqueratinizado exibindo 4 a 5 camadas de células. As células da camada basal são em paliçadas e a superfície corrugada. B. "Brotamento" das células epiteliais na cápsula cística. C. Células epiteliais odontogênicas presentes na cápsula fibrosa. D. Presença de cisto satélite na cápsula cística. 


\subsection{AVALIAÇÃO IMUNOISTOQUÍMICA}

\subsubsection{Grupos 1 e 2}

As reações imunoistoquímicas para a CQ 14 foram realizadas em 93 casos, 59 casos do Grupo 1 e 34 casos do Grupo 2. Houve predomínio da marcação B nos dois Grupos, observada em $51(86,44 \%)$ casos do Grupo 1 e 28 (82,35\%) casos do Grupo 2. A marcação BIS foi observada em $3(5,08 \%)$ casos do Grupo 1 e 3 (8,82\%) casos do Grupo 2. A marcação foi Inconclusiva em 5 (8,47\%) casos do Grupo 1 e 3 (8,82\%) do Grupo 2 (Tabela 5.5, Figura $5.4)$.

Para a CQ 17, as reações imunoistoquímicas foram realizadas em 90 casos, 58 casos do Grupo 1 e 32 casos do Grupo 2. A maioria dos casos houve marcação BIS observada em $50(86,21 \%)$ casos do Grupo 1 e $32(100 \%)$ casos do Grupo 2. Somente no Grupo 1 foi observada marcação BI, em $5(8,62 \%)$ casos. A marcação foi considerada inconclusiva somente em $3(5,17 \%)$ casos do Grupo 1 (Tabela 5.5, Figura 5.4).

Para a CQ 19, as reações imunoistoquímicas foram realizadas em 86 casos, 54 do Grupo 1 e 32 do Grupo 2. A marcação IS foi predominante sendo observada em 22 (40,74\%) casos do Grupo 1 e $15(46,88 \%)$ casos do Grupo 2. A marcação da camada basal foi observada em 11 (20,37\%) casos do Grupo 1 incluindo 3 casos que houve marcação basal e superficial. No Grupo 2, 2 (6,25\%), apresentaram marcação B. A marcação BIS foi encontrada em 7 (12,96\%) casos do Grupo 1 e 10 (31,25\%) casos do Grupo 2. Em 14 (24,5\%) casos do Grupo 1 e 5 (17,24\%) casos do Grupo 2, a marcação foi considerada Inconclusiva (Tabela 5.5, Figura 5.4).

Para o marcador p53, as reações imunoistoquímicas foram realizadas em 90 casos, 58 casos do Grupo 1 e 32 casos do Grupo 2. Para o Grupo 1, 50\% dos casos houve marcação entre 25-50\%. Para o Grupo 2, 43,75\% houve marcação $\geq 50 \%$ (Tabela 5.5, Figura 5.5). Entre os 90 casos avaliados, 83 casos (57 do Grupo 1 e 26 do Grupo 2) apresentaram marcação fraca (1+) sendo que a predominância de positividade concentrou entre 25-50\% em 44 casos (28 do Grupo 1 e 16 do Grupo 2) (Tabela 5.6).

Em geral, a marcação do ki-67 foi baixa sendo que para o Grupo 1, a média de positividade foi 21,96\% e para o Grupo 2, 27,11\% (Tabela 5.5, Figura 5.5). 
Tabela 5.5: Padrão de marcação dos anticorpos CQ14, CQ17, CQ19, p53, ki-67 para os TOQCs dos Grupos 1 (Não associoados a síndrome) e 2 (Sindrômicos).

\begin{tabular}{|c|c|c|c|c|c|c|c|}
\hline \multirow{2}{*}{ Anticorpos } & \multirow{2}{*}{ Marcação } & \multicolumn{2}{|r|}{1} & \multicolumn{2}{|r|}{2} & \multirow{2}{*}{ Total } & \multirow{2}{*}{$\mathbf{p}$} \\
\hline & & $\mathrm{n}$ & $\%$ & $\mathrm{n}$ & $\%$ & & \\
\hline \multirow{3}{*}{ CQ 14} & B & 51 & 86,44 & 28 & 82,35 & 79 & \multirow{3}{*}{0.806} \\
\hline & BIS & 3 & 5,08 & 3 & 8,82 & 6 & \\
\hline & In & 5 & 8,47 & 3 & 8,82 & 8 & \\
\hline \multirow[t]{2}{*}{ Total } & & 59 & 100 & 34 & 100 & 93 & \\
\hline & BIS & 50 & 86,21 & 32 & 100 & 82 & \multirow{3}{*}{0.092} \\
\hline \multirow[t]{2}{*}{ CQ17 } & $\mathrm{BI}$ & 5 & 8,62 & 0 & 0 & 5 & \\
\hline & In & 3 & 5,17 & 0 & 0 & 3 & \\
\hline \multirow[t]{2}{*}{ Total } & & 58 & 100 & 32 & 100 & 90 & \\
\hline & IS & 22 & 40,74 & 15 & 46,88 & 37 & \multirow{4}{*}{0.069} \\
\hline \multirow[t]{3}{*}{ CQ 19} & B & 11 & 20,37 & 2 & 6,25 & 13 & \\
\hline & BIS & 7 & 12,96 & 10 & 31,25 & 17 & \\
\hline & In & 14 & 25,93 & 5 & 15,63 & 19 & \\
\hline Total & & 54 & 100 & 32 & 100 & 86 & \\
\hline \multirow{4}{*}{ p53 } & $<10 \%$ & 7 & 12,0 & 2 & 6,2 & 9 & \multirow{4}{*}{0.215} \\
\hline & $10-25 \%$ & 9 & 15,5 & 4 & 12,5 & 13 & \\
\hline & $25-50 \%$ & 29 & 50 & 12 & 37,5 & 41 & \\
\hline & $\geq 50 \%$ & 13 & 22,4 & 14 & 43,7 & 27 & \\
\hline \multirow[t]{3}{*}{ Total } & & 58 & 100 & 32 & 100 & 90 & \\
\hline & Média & & 21,96 & & 27,11 & & \multirow{5}{*}{0.049} \\
\hline & Desvio-padrão & & 10,95 & & 13,11 & & \\
\hline \multirow[t]{3}{*}{ Ki-67 } & Mínimo & & 0,49 & & 7,74 & & \\
\hline & Mediana & & 21,32 & & 27,05 & & \\
\hline & Máximo & & 48,04 & & 57,89 & & \\
\hline Total & & 58 & & 32 & & 90 & \\
\hline
\end{tabular}

$\mathrm{B}=$ camada Basal, BIS=camadas Basal, Intermediária e Superficial, In=marcação Inconclusiva, BI=camadas Basal e Intemediária, IS=marcação Intermediária e Superficial. 
Tabela 5.6: Correlação entre a positividade de células e intensidade da marcação para o p53 nos Grupos 1 e 2.

\begin{tabular}{cccccccc}
\hline $\mathbf{p 5 3}$ & \multicolumn{2}{c}{$1+$} & \multicolumn{2}{c}{$\mathbf{2 +}$} & \multicolumn{2}{c}{ 3+ } & Total \\
\cline { 1 - 7 } & G1 & G2 & G1 & G2 & G1 & G2 & \\
\cline { 2 - 7 } & 8 & 3 & 0 & 0 & 0 & 0 & 11 \\
$\mathbf{1 0 \% - 2 5 \%}$ & 21 & 6 & 0 & 0 & 0 & 0 & 27 \\
$\mathbf{2 5 \% - 5 0 \%}$ & 28 & 16 & 4 & 1 & 0 & 2 & 51 \\
$\geq \mathbf{5 0 \%}$ & 0 & 1 & 0 & 0 & 0 & 0 & 1 \\
\hline Total & 57 & 26 & 4 & 1 & 0 & 2 & 90 \\
\hline
\end{tabular}
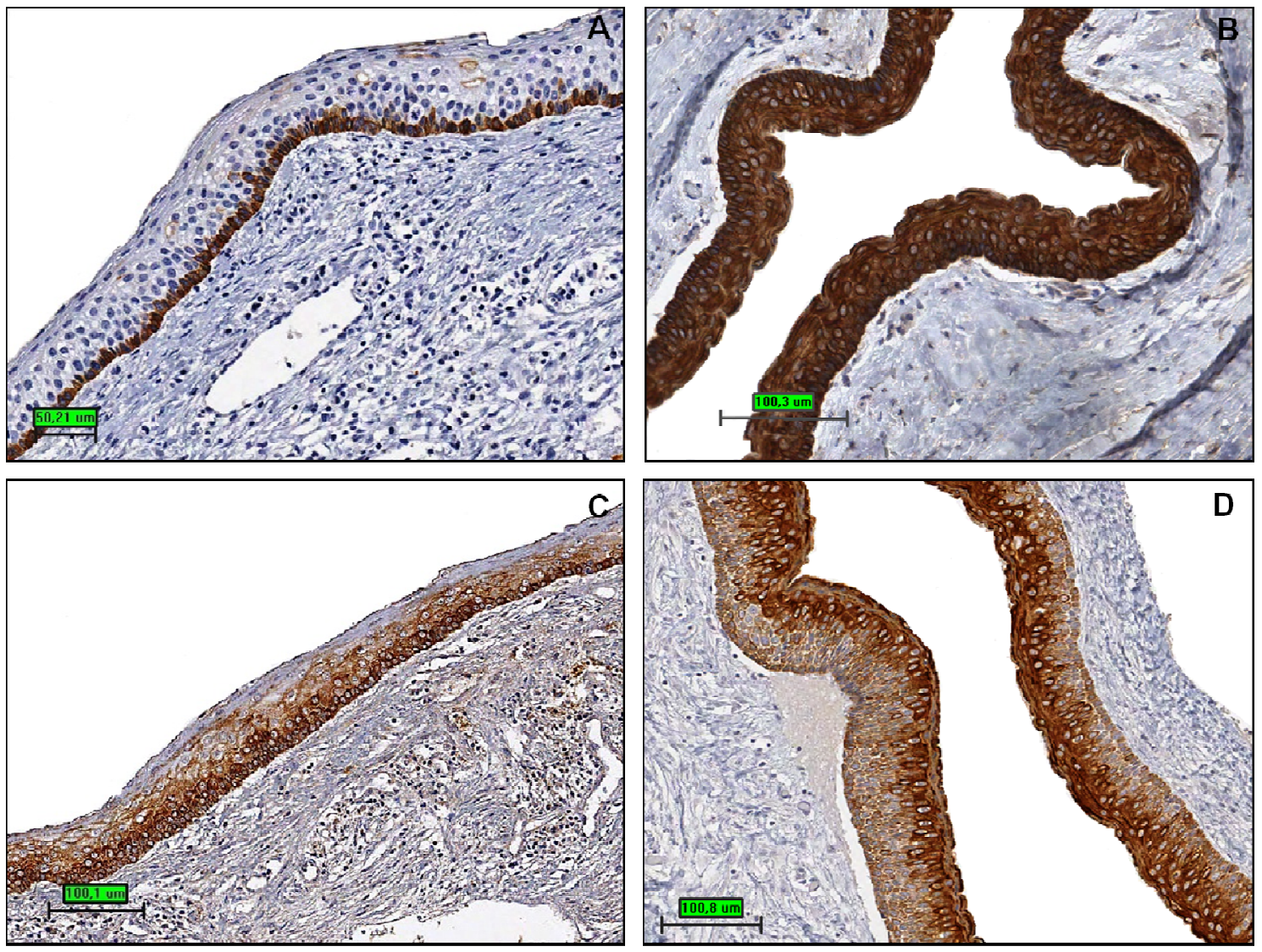

Figura 5.4: Padrões de marcação das CQ 14, CQ 17 e 19 em TOQCs (IHQ). A. Marcação basal da CQ 14 em TOQC não associado à SCNBC. B. Marcação das camadas basal, intermediária e superficial da CQ 17 em TOQC não associado à SCNBC. C. Marcação epitelial da CQ 17 predominantemente nas camadas basal e intermediária em TOQC não associado à SCNBC. D. Marcação epitelial da CQ 19 nas camadas intermediárias e superficiais em TOQC não associado à SCNBC. 

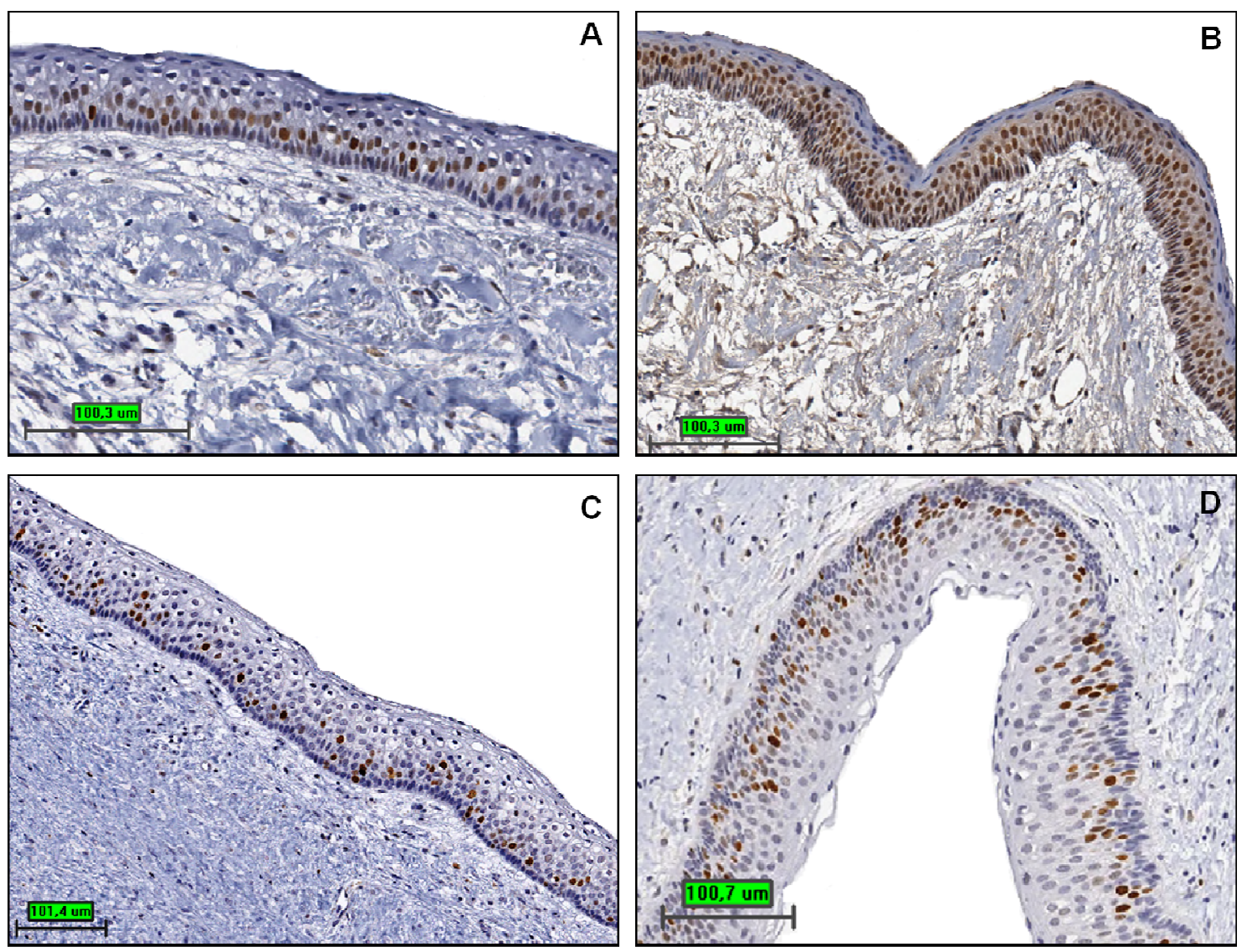

Figura 5.5: Padrões de marcação do p53 e Ki-67 (IHQ). A. Marcação do p53 em 36,57\% em TOQC não associado à SCNBC. B. Marcação do p53 de 61,29\% em TOQC associado à SCNBC. C. Marcação positiva do Ki-67 em 13,84\% em TOQC não associado à SCNBC. D. Marcação positiva do Ki-67 em 23,32\% em TOQC associado à SCNBC.

\subsubsection{Grupos P (primários) e R (recidivados)}

As reações imunoistoquímicas da CQ 14 foram realizadas em 93 casos, sendo 77 do Grupo P e 16 do Grupo R. A marcação B foi predominante sendo observada em 63 (81,82\%) casos no grupo P e 16 (100\%) no grupo R. A marcação BIS foi observada somente no Grupo P, em $6(7,79 \%)$ casos. Em $8(10,39 \%)$ casos do mesmo Grupo a marcação foi considerada inconclusiva (Tabela 5.7). Nos casos que apresentaram recidiva, o padrão de marcação basal permaneceu o mesmo que a lesão primária em 12 casos (Tabela 5.8).

Para a CQ 17, as reações imunoistoquímicas foram realizadas em 90 casos, 75 casos do Grupo P e 15 casos do Grupo R. A marcação BIS foi predominante sendo observada em 69 (92\%) casos do Grupo P e $13(86,67 \%)$ casos do Grupo R. A marcação BI foi encontrada 
somente no Grupo P em 3 (4\%) casos. Em 3 (4\%) casos do Grupo P e 2 (13,33\%) casos do Grupo R, a marcação foi considerada inconclusiva (Tabela 5.7). Nos TOQCs que apresentaram recidiva, o padrão de marcação BIS permaneceu o mesmo da lesão primária em 9 dos 10 casos onde esta informação foi possível avaliar (Tabela 5.8).

Para a CQ 19, as reações imunoístoquímicas foram realizadas em 86 casos, 70 do Grupo P e 16 do Grupo R. A marcação IS foi mais predominante sendo observada em 29 $(41,43 \%)$ casos do Grupo P e 8 (50\%) casos do Grupo R. Em 13 (18,5\%) casos do Grupo P e 4 (25\%) casos do Grupo R foi encontrada marcação BIS. A marcação B foi observada em 12 $(17,14 \%)$ casos do Grupo P incluindo 2 casos que apresentaram marcação B associada à marcação superficial. No Grupo R houve marcação B em apenas 1 (6,25\%) caso. A marcação foi inconclusiva em 16 (22,86\%) casos do Grupo P e 3 (18,75\%) casos do Grupo R (Tabela 5.7). Nos casos que havia disponibilidade de TOQCs $\mathrm{P}$ e $\mathrm{R}$ do mesmo paciente houve mudança no padrão de marcação B em 2 casos. A marcação IS foi observada em 4 tumores primários e 5 recidivados. A marcação BIS foi encontrada em 4 tumores primários e 3 recidivados e a inconclusiva em 1 primário e 3 recidivados (Tabela 5.8).

Para o marcador p53 as reações imunoistoquímicas foram realizadas em 90 casos, 75 casos do Grupo P e 15 casos do Grupo 2. Houve predominância de marcação em 25-50\% de positividade nos dois Grupos, 34 (45,33\%) casos para o Grupo P e 7 (46,67\%) casos no Grupo R (Tabela 5.7). Em 11 casos que havia disponibilidade tanto do TOQC P quanto do TOQC R do mesmo paciente, foi observado que 4 pacientes mudaram o padrão de marcação de $>25 \%$ de positividade na lesão primária para $\leq 25 \%$ na lesão recidivada (Tabela 5.8, Figura $5.6)$.

O marcador ki-67, mostrou uma média de marcação de 24\% no Grupo P e 22,74\% no Grupo R (Tabela 5.7). 
Tabela 5.7: Padrão de marcação da CQ 14, CQ 17, p53 e Ki-67 para os tumores Primários e Recidivados.

\begin{tabular}{|c|c|c|c|c|c|c|}
\hline \multirow{2}{*}{ Anticorpos } & \multirow{2}{*}{ Marcação } & \multicolumn{2}{|c|}{$\mathbf{P}$} & \multicolumn{2}{|r|}{$\mathbf{R}$} & \multirow{2}{*}{ Total } \\
\hline & & $\mathrm{n}$ & $\%$ & $\mathrm{n}$ & $\%$ & \\
\hline \multirow{3}{*}{ CQ 14} & B & 63 & 81,82 & 16 & 100 & 79 \\
\hline & BIS & 6 & 7,79 & 0 & 0 & 6 \\
\hline & In & 8 & 10,39 & 0 & 0 & 8 \\
\hline Total & & 77 & 100 & 16 & 100 & 93 \\
\hline \multirow{3}{*}{ CQ 17} & BIS & 69 & 92 & 13 & 86,67 & 82 \\
\hline & BI & 3 & 4 & 0 & 0 & 3 \\
\hline & In & 3 & 4 & 2 & 13,33 & 5 \\
\hline Total & & 75 & 100 & 15 & 15 & 90 \\
\hline \multirow{4}{*}{ CQ 19} & IS & 29 & 41,43 & 8 & 50 & 37 \\
\hline & BIS & 13 & 18,57 & 4 & 25 & 17 \\
\hline & B & 12 & 17,14 & 1 & 6,25 & 13 \\
\hline & In & 16 & 22,86 & 3 & 18,75 & 19 \\
\hline Total & & 70 & 100 & 16 & 100 & 86 \\
\hline \multirow{4}{*}{ p53 } & $<10 \%$ & 5 & 6,67 & 4 & 26,67 & 9 \\
\hline & $10-25 \%$ & 12 & 16 & 1 & 6,56 & 13 \\
\hline & $25-50 \%$ & 34 & 43,33 & 7 & 46,67 & 41 \\
\hline & $\geq 50 \%$ & 24 & 32 & 3 & 20 & 27 \\
\hline Total & & 75 & 100 & 15 & 100 & 90 \\
\hline \multirow{5}{*}{ Ki-67 } & Média & & 24 & & 22,74 & \\
\hline & Desvio-padrão & & 11,24 & & 15,46 & \\
\hline & Mínimo & & 2,11 & & 0,49 & \\
\hline & Mediana & & 23,21 & & 23,66 & \\
\hline & Máximo & & 50,84 & & 57,89 & \\
\hline Total & & 75 & & 15 & & 90 \\
\hline
\end{tabular}

$\mathrm{B}=$ camada Basal, BIS=camadas Basal, Intermediária e Superficial, $\mathrm{In}=$ marcação Inconclusiva, $\mathrm{BI}=$ camadas Basal e Intemediária, IS=marcação Intermediária e Superficial. 
Tabela 5.8: Padrão de marcação do TOQC para a CQ 14, CQ 17 e p53 para lesões primárias e recidivadas.

\begin{tabular}{llll}
\hline Marcador & Marcação & Primária & Recidiva \\
\hline CQ14 (12 casos) & B & 12 & 12 \\
\hline CQ17 (10 casos) & BIS & 10 & 9 \\
& BI & 0 & 1 \\
\hline CQ 19 (11 casos) & B & 2 & 0 \\
& IS & 4 & 5 \\
& BIS & 4 & 3 \\
& In & 1 & 3 \\
\hline p53 (10 casos) & $\leq 25 \%$ & 0 & 4 \\
& $>25 \%$ & 10 & 6
\end{tabular}

$\mathrm{B}=$ Camada Basal, BIS=Camadas Basal,
Intermediária e Superficial, BI=Camadas Basal e Intermediária, IS=Camadas Intermediária e Superficial.

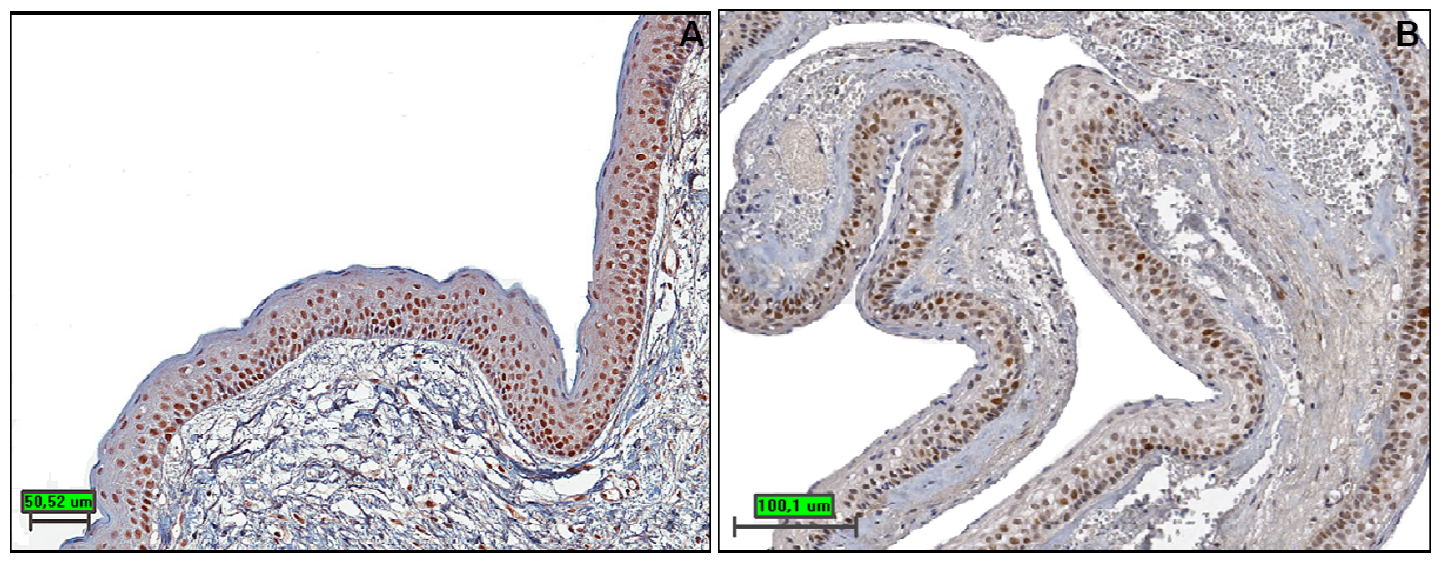

Figura 5.6: Padrão de marcação do p53 em tumor primário e recidivado do mesmo paciente (IHQ). A. Marcação em 78,09\% do TOQC primário. B. Marcação em 48,28\% do TOQC recidivado. 


\section{DISCUSSÃO}

A SCNBC (Síndrome do Carcinoma Nevóide Basocelular) é uma desordem autossômica dominante causada por mutações no gene PTCH. Em 70-80\% dos pacientes, a síndrome é herdada dos pais e cerca de $20-30 \%$ possui uma mutação de novo. Atualmente, Evans e Farndon (2010) propuseram novos critérios devido à viabilidade de testes moleculares com os quais ampliaram o espectro fenotípico da síndrome. Estes autores modificaram dois critérios maiores: os pacientes devem apresentar mais de 5 Carcinomas Baso-Celulares (CBCs) durante a vida ou 1 CBC antes dos 30 anos de idade. Costelas bífidas, fusionadas, extranumerárias passaram para os critérios menores. Além disso, foram adicionados aos critérios menores cistos linfomesentéricos e anomalias oculares como cataratas, anomalias de desenvolvimento e alterações pigmentares no epitélio da retina.

Nos resultados aqui apresentados, as manifestações mais comuns, além dos TOQCs, foram CBCs, "pits" palmares e calcificação da foice cerebral. De acordo com o estudo de 105 indivíduos de Kimonis et al. (1997), as manifestações mais freqüentes foram CBCs (80\% em pacientes leucodermas), TOQCs (74\%), "pits” palmares e plantares $(87 \%)$ e ,calcificação da foice cerebral (65\%).

Aproximadamente 5\% dos indivíduos com síndrome desenvolvem meduloblastoma. $\mathrm{O}$ meduloblastoma isolado acomete crianças com aproximadamente 7 anos de idade, no entanto a maior incidência passa para os 2 anos de idade quando associados à SCNBC (Cowan 1997, Amlashi et al., 2003). O tratamento dos pacientes com síndrome requer atenção especial, pois a radioterapia pode induzir CBCs no campo de radiação ou tumores craniais e nasais (Maringutzke et al., 2004; Choudry et al., 2007; Wallin et al., 2007). O atual estudo mostrou 1 paciente que apresentou meduloblastoma com 3 anos de idade e aos 17 anos evoluiu com 3 TOQCs sincrônicos. Até então, o paciente não apresentava critérios suficientes para o diagnóstico da SCNBC. No entanto, aos 18 anos, foi observada a presença de calcificação da foice cerebral e o diagnóstico da síndrome foi estabelecido.

De acordo com a classificação mais recente (Evans; Farndon 2010) a calcificação da foice cerebral é um dos critérios maiores para a síndrome em pacientes abaixo dos 20 anos de idade. Kimonis et al. (1997) avaliaram a calcificação da foice cerebral em 82 indivíduos com síndrome. A calcificação estava presente em 23 de 29 (79\%) indivíduos com idade superior a 40 anos, 20/26 (77\%) entre 20 e 40 anos e 10/27 (37\%) inferior a 20 anos de idade. 
Em indivíduos jovens, o TOQC é uma das manifestações mais consistentes e representativas da síndrome e pode afetar até $100 \%$ dos pacientes sindrômicos (Habibi; Jafarzadeh 2010). No estudo de Lo Muzio et al (1999), dentre os 37 indivíduos avaliados, o TOQC foi a primeira manifestação da SCNBC em 67,5\%. No presente estudo, foram avaliados 74 pacientes com TOQCs, sendo que 14 (19,17\%) possuem associação com a síndrome. Entre estes pacientes, 8 (57,14\%) desenvolveram TOQCs como primeiro sinal da síndrome.

Os tumores odontogênicos (TO) são raros e representam cerca de 0,7 a 2,7\% de todas as lesões orais (Mosqueda-Taylor et al., 1997, Santos et al., 2001, Buchner A et al., 2006; Ochsenius G, 2002). De acordo com a literatura atual, existe uma variação na incidência de TOs ao considerar a nova classificação da OMS (Barnes et al. 2005). Os levantamentos epidemiológicos de Avelar et al. (2008) e Luo et al.(2010) mostraram maior incidência dos TOQCs, seguido pelos ameloblastomas e odontomas, respectivamente. Nos estudos de Tawfik et al. (2010) e Osterne et al. (2011), o ameloblastoma é o tumor mais freqüente, seguido pelos TOQCs e odontomas. De acordo com Sriram et al. (2008) esta variação de incidência pode estar associada à região geográfica estudada. Fregnani et al (2002) mostrou que existe variação na incidência de tumores odontogênicos entre instituições localizadas na mesma região geográfica. Instituições que se restringem somente a atendimento odontológico possuem odontoma como tumor mais freqüente, no entanto, em instituições que priorizam atendimento médico e cirúrgico, o ameloblastoma possui maior incidência.

O presente estudo possui uma amostra de 92 TOQCs primários sendo que 31 (34,06\%) casos possuem associação à síndrome. Na casuística de Myoung et al. (2001), apenas 4,3\% dos TOQCs, em uma série de 256 TOQCs, estavam associados à SCNBC.

Considerando o grupo de 60 pacientes com TOQCs primários não associados à SCNBC, 46,67\% dos pacientes pertencem ao sexo masculino e 53,33\% ao feminino. Na série de 484 pacientes não portadores da síndrome do estudo de Zhao et al. (2002) houve predomínio em homens $(65,91 \%)$. No atual estudo, para o grupo de 14 pacientes com TOQCs primários associados à SCNBC houve uma predileção pelo sexo feminino $(64,29 \%)$. Em concordância, Gonzáles-Alva et al. (2008), mostraram maior prevalência em mulheres $(63,6 \%)$ do total de 11 pacientes com TOQCs associados à síndrome. Em estudos retrospectivos da SCNBC, independentemente da associação com TOQCs, não existem diferenças na incidência entre os gêneros (Ahn et al., 2004; Habib; Jafarzadeh, 2010; Jones et al., 2011). 
Nos pacientes com TOQCs isolados, a faixa etária mais comum foi observada entre as $3^{\mathrm{a}}$ e $4^{\mathrm{a}}$ décadas de vida, semelhante ao estudo de 261 casos de TOQCs de Boffano et al. (2010). Em TOQCs associados à SCNBC, a $2^{\text {a }}$ década de vida foi a idade mais acometida e um segundo pico ocorreu na $4^{\text {a }}$ década. Da mesma maneira, Ahn et al (2004) avaliaram 30 pacientes com TOQCs associados à SCNBC e o maior número de casos ocorreu em pacientes entre as $1^{\mathrm{a}}$ e $2^{\mathrm{a}}$ décadas de vida.

No atual estudo, houve predomínio da raça branca nos grupos de pacientes com TOQCs associados e não associados à $\operatorname{SCNBC}(92,31 \%$ e 83,33\%, respectivamente). A literatura mostra que pacientes leucodermas são mais comumente afetados pela SCNBC (Manfredi et al., 2004). Com isso, a tendência do desenvolvimento de CBCs é maior devido à maior sensibilidade aos raios ultravioletas (UV) (Shanley et al., 1994).

Myoung et al. (2001) avaliaram sinais e sintomas dos 256 pacientes com TOQCs e 46,1\% referiram inchaço, 19,9\% apresentavam sintomatologia dolorosa e 16,4\% queixavamse de inchaço e dor simultaneamente. Outras manifestações menos comuns foram secreção purulenta $(6,6 \%)$ e parestesia $(0,8 \%)$. Pacientes que não apresentavam queixas e a lesão foi descoberta através da radiografia panorâmica de rotina corresponderam a 5,5\%. No presente estudo, ao avaliar a queixa principal, observamos que, em ambos os grupos, inchaço foi referido por $41,67 \%$ dos pacientes sem SCNBC e 38,46\% em pacientes com SCNBC. Sintomatologia dolorosa ou dor associada ao inchaço (11,67\% e 5\%, respectivamente) foram observadas apenas no grupo de pacientes com TOQCs esporádicos. Os pacientes que não apresentaram queixas e as lesões descobertas em radiografia de rotina representam $23,33 \%$ do grupo de TOQCs sem SCNBC e 53,85\% no grupo com SCNBC.

TOQCs múltiplos são frequentemente observados em pacientes com síndrome (Evans; Farndon 2010). Neste estudo foi observado que 60 pacientes não portadores da SCNBC apresentaram 61 TOQCs primários e 14 pacientes portadores da SCNBC apresentaram 31 TOQCs primários. Isso mostra que tumores múltiplos são freqüentes em pacientes com SCNBC ( $<$ 0.001). Chirapathomsakul et al. (2006) avaliaram 51 pacientes que apresentaram 67 TOQCs e destes pacientes, 6 apresentaram múltiplos TOQCs. No entanto, não foi descrito se havia ou não associação dos TOQCs com SCNBC. Na casuística de Myoung et al. (2001), todos os pacientes portadores da SCNBC apresentaram TOQCs múltiplos. No presente estudo, dos 14 pacientes portadores da síndrome, 8 apresentaram TOQCs isolados e 6 apresentaram múltiplos tumores. Entre estes últimos, 4 apresentaram o total de 15 tumores sincrônicos e 1 paciente apresentou 3 lesões metacrônicas. O sexto paciente apresentou 2 
tumores sincrônicos na primeira consulta e durante o período de acompanhamento evoluiu com 3 lesões metacrônicas.

Diversos estudos evidenciam que a mandíbula é a localização mais frequentemente acometida pelos TOQCs (Myoung et al., 2001; Zhao et al., 2002; Gonzáles-Alva et al., 2008). Na maior casuística da literatura, Woolgar et al. (1987) revelaram que a mandíbula, mais precisamente a região de molares, foi mais acometida em 379 tumores isolados e 164 tumores sindrômicos. Ao avaliar 183 casos de TOQCs, Gonzáles-Alva et al. (2008) observaram maior incidência na região de molares $(41 \%)$ e apenas $7,8 \%$ na região de ramo mandibular. Da mesma forma, no presente estudo, tanto o grupo de TOQCs esporádicos quanto no grupo de TOQCs sindrômicos, a mandíbula foi a região mais acometida. No grupo de TOQCs associados à síndrome, a discrepância dos tumores entre maxila e mandíbula foi menor do que no grupo de TOQCs esporádicos $(\mathrm{p}=0.009)$. Este achado foi observado também na casuística de Woolgar et al. (1987) concluindo que este fato pode estar associado à ocorrência de múlitplos TOQCs neste grupo de pacientes.

Bataineh e al Qudah (1998) avaliaram 31 TOQCs e 61,29\% tinham aspecto multilocular e 38,70\%, unilocular. No estudo de Zhao et al. (2002), 83,02\% dos TOQCs eram uniloculares e 16,98\% multiloculares. Não havia referência em relação à associação com a SCNBC nos estudos citados acima. Em nosso estudo, no grupo de TOQCs não associados à síndrome, o padrão radiográfico mais predominante foi multilocular (60\%). Já no grupo de TOQCs associados à síndrome, 66\% dos casos eram uniloculares.

Em ambos os grupos avaliados neste estudo, a técnica mais utilizada foi associação de enucleação e curetagem. A associação de enucleação, curetagem e crioterapia foi realizada somente em pacientes com TOQCs esporádicos (20 casos). Dois pacientes com TOQCs isolados e 1 paciente com TOQC sindrômico realizaram marsupialização e posterior curetagem. Quanto às taxas de recorrência, não houve diferença significativa nos grupos estudados durante o seguimento médio de 83,8 e 78,44 meses $(21,31 \%$ em TOQCs esporádicos e 22,58\% em TOQCs associados à síndrome).

Na série de Zhao et al. (2002) foram realizadas quatro terapias distintas: 163 pacientes tratados por enucleação, 29 por enucleação associada à solução de carnoy, 11 por marsupialização e posterior enucleação e 52 por ressecção. A terapia com maior índice de recorrência foi enucleação cística $(17,79 \%)$, seguida pela associação de enucleação e solução de carnoy $(6,7 \%)$. As outras modalidades não apresentaram recorrência em um período de acompanhamento de 2 a 13 anos. 
Diversas modalidades de tratamento são realizadas em TOQCs, desde terapias conservadoras a terapias invasivas. Apesar de o TOQC ser considerado tumor benigno, técnicas conservadoras devem ser priorizadas devido à baixa taxa de morbidade e posteriormente poder proporcionar melhor qualidade de vida aos pacientes. No entanto um longo período de acompanhamento deve ser realizado principalmente em pacientes portadores da SCNBC, nos quais possuem tendência a desenvolver múltiplos tumores.

Recentemente, estratégias de tratamentos moleculares relacionados à cascata de sinalização do PTCH têm buscado novas perspectivas quanto ao desenvolvimento de drogas no tratamento das manifestações associadas à síndrome como os CBCs e TOQCs (Williams et al., 2003, Mendes et al., 2010a). A ciclopamina, por exemplo, age através do bloqueio da atividade excessiva do SHH, impedindo o crescimento tumoral (Taipale et al., 2000). Zhang et al. (2001) sugerem que antagonistas da cascata de sinalização do SHH podem apresentar efeitos significativos no tratamento dos TOQCs. Os autores suportam a idéia de que a aplicação intralesional de proteínas antagonistas ao SMO pode também ser um tratamento efetivo.

Muitos estudos sobre a expressão das citoqueratinas (CQ) têm sido realizados com intuito de determinar o padrão de expressão e elucidar a natureza neoplásica do TOQC (Shear, 2002a). Santos et al. (2009) avaliaram a imunoexpressão das CQ 7, 8, 10, 13, 14, 18 e 19 em 25 TOQCs, subdivididos em lesões primárias, recorrentes e associadas à síndrome. A CQ 14 mostrou marcação em todas as camadas epiteliais, incluindo áreas de inflamação. Além disso, outras áreas do mesmo tumor mostraram perda de marcação com preservação somente da camada basal. O presente estudo mostrou que a CQ 14 apresenta predominância da marcação basal em todas as amostras de TOQCs, tanto em TOQCs associados e não associados à SCNBC, assim como em TOQCs recidivados e recorrentes.

Meara et al. (2000) avaliaram a marcação das proteínas CQ 13, 17 e 18 e CQAE1/AE3 em diversas lesões incluindo 4 casos de ameloblastomas, 7 cistos dentígeros, 7 TOQCs primários e 6 TOQCs recorrentes associados à SCNBC. Foram encontradas diferenças significantes somente com a marcação da CQ 17, mostrando que em ameloblastomas e cistos dentígeros foram encontradas marcações fracas e descontínuas. Em 100\% dos TOQCs recorrentes associados à SCNBC a marcação foi intensa e uniforme em todas as camadas do epitélio. Já em 7 TOQCs primários, 4 apresentaram marcações fracas e irregulares e 3 tumores mostraram marcação intensa em todo epitélio. No presente estudo, houve marcação intensa da CQ 17 em todas as camadas do epitélio em todos os 32 casos de TOQCs associados à SCNBC. Dentre os TOQCs esporádicos, 48 (82,7\%) também apresentaram este 
padrão de marcação. Em TOQCs primários e recidivados houve marcação similar da CQ 17, sendo que o padrão de marcação mais encontrado, também, foi observado em todas as camadas epiteliais.

Stoll et al. (2005) estudaram a expressão imunoistoquímica das CQs 5/6, 7, 10, 13, 17 , 19 e 20 em 30 cistos odontogênicos, 30 cistos dentígeros e 15 TOQCs. A marcação da CQ 17 obtida também foi intensa em todas as camadas do epitélio em 14 dos 15 tumores estudados. No entanto, não foi revelado se havia associação dos TOQCs com a SCNBC ou se eram lesões primárias ou recorrentes. Além disso, foi observada negatividade para a CQ 19 em todos os casos de TOQCs avaliados, diferente dos cistos avaliados no estudo. Os autores concluíram que a expressão das CQs 17 e 19 podem ajudar a distinguir os TOQCs dos cistos odontogênicos avaliados no estudo. Santos et al. (2009) mostraram resultados diferentes ao observar que em 52\% dos 25 casos a marcação da CQ 19 foi observada em todas as camadas epiteliais, $40 \%$ mostrou marcação nas camadas intermediárias e superficiais e apenas 1 mostrou negatividade. De acordo com o presente estudo, a marcação da CQ 19 foi predominante nas regiões intermediárias e superficiais do epitélio em todos os grupos avaliados. Em parte da amostra foi observada marcação fraca e inconsistente que foi considerada como marcação inconclusiva. Os diferentes resultados observados nos estudos acima podem ser resultado do uso de diferentes clones.

A atividade proliferativa do revestimento epitelial dos TOQCs é alvo de diversos estudos imunoistoquímicos como os marcadores de proliferação celular e apoptose: p53, ki-67 e PCNA (proliferating cell nuclear antigen). A imunoexpressão destes marcadores é maior em TOQCs quando comparados a outros cistos odontogênicos (Li et al., 1995; Shear et al., 2002b; Mateus et al., 2008; Ayoub et al., 2011). Ao avaliar a imunoexpressão de diferentes clones do p53, Li et al. (1996) concluíram que o aumento da expressão comparado a outros cistos odontogênicos não é resultado da mutação no gene TP53 mas sim resultado de uma maior produção e/ou estabilização da proteína p53 do tipo selvagem. Clones do anticorpo p53 podem reconhecer não somente p53 mutado, mas também p53 selvagem. Assim, não se pode implicar que a positividade desta proteína esteja associada a desordens malignas (Ogden et al., 1992). No atual estudo, o clone DO-7 reconhece ambas as formas da proteína p53.

Lombardi et al. (1995) avaliaram a expressão do p53 em 15 TOQCs não recorrentes, 10 recorrentes e 5 sindrômicos e os resultados mostraram padrão de marcação fraco e irregular. Não houve diferenças na expressão entre os grupos estudados. O presente estudo mostrou semelhança da imunoexpressão do p53 entre os grupos de TOQCs esporádicos e sindrômicos. Assim como em TOQCs primários e recorrentes. Foi observado também que a 
positividade do p53 do tumor primário e recidivado do mesmo paciente mudaram de comportamento, ou seja, 4 tumores passaram a expressar menos a proteína p53 na recorrência. A intensidade da marcação do p53 foi fraca (1+) na maior parte dos TOQCs nos dois grupos estudados. Em relação aos tumores malignos orais, a intensidade da marcação do p53 observada em TOQCs é acentuadamente inferior (Ogden et al., 1996).

Gurgel et al. (2008) avaliaram uma amostra de 37 TOQCs e observaram que a positividade do ki-67 em TOQCs isolados foi encontrada exclusivamente na camada suprabasal do epitélio, ao passo que em TOQCs associados à síndrome, esta marcação foi observada em todas as camadas de células epiteliais. No entanto, a espessura do epitélio do TOQC é limitada, o que pode dificultar a análise da expressão em sua exata localização (Mendes et al., 2010b). Ayoub et al. (2011) avaliaram a expressão dos marcadores ki-67 e laminina 1 em 13 cistos radiculares e 14 TOQCs. O marcador ki-67 apresentou positividade em 53,8\% das amostras de cistos radiculares e o autor relacionou esta expressão com a presença de inflamação. Todos os casos de TOQCs apresentaram positividade para este marcador. Nosso estudo mostrou que apesar de haver expressão em 100\% dos casos, o índice de positividade foi baixo. A média de positividade em TOQCs esporádicos e associados à SCNBC foi semelhante $(26,68 \%$ e $22,27 \%$, respectivamente). Assim como em TOQCs recidivados, a média de positividade de ki-67 foi de 22,74\%, e em TOQCs primários foi de 23,9\%. Da mesma forma, Mateus et al. (2008) avaliaram 11 TOQCs esporádicos, 15 TOQCs associados à síndrome, 11 cistos dentígeros e não observaram diferenças na expressão do marcador ki-67 em TOQCs esporádicos e associados à SCNBC. No entanto, a marcação nestes grupos foi maior do que em cistos dentígeros. Igualmente, Mendes et al. (2011) não encontraram resultados relevantes na associação expressão dos marcadores, COX-2, ki-67 e p53 em 20 TOQCs, divididos em 18 esporádicos e 2 sindrômicos, 15 primários e 5 recorrentes.

Em resumo, o TOQC é um tumor odontogênico raro. No entanto, sua manifestação em pacientes com SCNBC é frequentemente observado. Pode-se apresentar como primeiro sinal da síndrome em pacientes jovens e múltiplos tumores podem ser observados. Devido à gravidade das manifestações clínicas observadas na síndrome, deve-se salientar o diagnóstico precoce assim como um longo período de acompanhamento dos pacientes. Os resultados imunoistoquímicos não mostraram resultados relevantes entre os grupos de TOQCs avaliados. 


\section{CONCLUSÕES}

A partir dos resultados obtidos neste estudo podemos concluir que:

1. Os TOQCs associados à SCNBC acometem mais frequentemente indivíduos do sexo feminino e em idade mais precoce do que os TOQCs esporádicos,

2. Múltiplos TOQCs foram frequentemente observados em pacientes sindrômicos e consequentemente houve menor discrepância em relação à sua distribuição entre mandíbula e maxila,

3. O aspecto radiográfico unilocular é mais frequente em TOQCs associados à SCNBC e multilocular em TOQCs esporádicos,

4. As taxas de recorrência foram similares em TOQCs associados e não associados à SCNBC,

5. Não houve diferenças no padrão de marcação das CQ entre os Grupos de TOQCs associados e não associados à SCNBC, bem como em TOQCs primários e recidivados,

6. A imunoexpressão dos marcadores p53 e ki-67 foram semelhantes em TOQCs associados e não associados à síndrome e em TOQCs primários e recidivados. 


\section{REFERÊENIAS ${ }^{1}$}

Agaram NP, Collins BM, Barnes L, Lomago D, Aldeeb D, Swalsky P, Finkelstein S, Hunt JL. Molecular analysis to demonstrate that odontogenic keratocysts are neoplastic. Arch Pathol Lab Med. 2004;128(3):313-7.

Ahn SG, Lim YS, Kim DK, Kim SG, Lee SH, Yoon JH. Nevoid basal cell carcinoma syndrome: a retrospective analysis of 33 affected Korean individuals. Int J Oral Maxillofac Surg. 2004;33(5):458-62.

Amezaga AOG, Arregui OG, Nuño SZ, Sagredo AA, Urizar JMA. Gorlin-Goltz syndrome: clinicopathologic aspects. Med Oral Patol Oral Cir Bucal. 2008;13(6):338-43.

Amlashi SF, Riffaud L, Brassier G, Morandi X. Nevoid basal cell carcinoma syndrome: relation with desmoplastic medulloblastoma in infancy. A population-based study and review of the literature. Cancer 2003;98(3):618-24

Aragaki T, Michi Y, Katsube K, Uzawa N, Okada N, Akashi T, Amagasa T, Yamaguchi A, Sakamoto K. Comprehensive keratin profiling reveals different histopathogenesis of keratocystic odontogenic tumor and orthokeratinized odontogenic cyst. Hum Pathol. 2010;41(12):1718-25.

Avelar RL, Antunes AA, Santos Tde S, Andrade ES, Dourado E. Odontogenic tumors: clinical and pathology study of 238 cases. Braz J Otorhinolaryngol. 2008;74(5):668-73.

Ayoub MS, Baghdadi HM, El-Kholy M. Immunohistochemical detection of laminin-1 and Ki-67 in radicular cysts and keratocystic odontogenic tumors. BMC Clin Pathol. 2011;11:4.

Barnes L, Eveson JW, Reichart P, Sidransky D, editors. Pathology and genetics of head and neck tumours. Lyon: IARC Press; 2005. WHO classification of tumours series.

Barreto DC, Gomez RS, Bale AE, Boson WL, De Marco L. PTCH gene mutations in odontogenic keratocysts. J Dent Res. 2000;79(6):1418-22

Bataineh AB, al Qudah M. Treatment of mandibular odontogenic keratocysts. Oral Surg Oral Med Oral Pathol Oral Radiol Endod;1998;86(1):42-7.

\footnotetext{
${ }^{1}$ De acordo com o estilo Vancouver
} 
Bitar GJ, Herman CK, Dahman MI, Hoard MA. Basal cell nevus syndrome: guidelines for early detection. Am Fam Physician. 2002;65(12):2501-4.

Boffano P, Ruga E, Gallesio C. Keratocystic odontogenic tumor (odontogenic keratocyst): preliminary retrospective review of epidemiologic, clinical, and radiologic features of 261 lesions from University of Turin. J Oral Maxillofac Surg. 2010; 68(12):29949.

Brannon RB. The odontogenic keratocyst. A clinicopathologic study of 312 cases. Part I. Clinical features. Oral Surg Oral Med Oral Pathol 1976; 42(1):54-72.

Buchner A, Merrell PW, Carpenter WM. Relative frequency of central odontogenic tumors: a study of 1,088 cases from Northern California and comparison to studies from other parts of the world. J Oral Maxillofac Surg. 2006 Sep;64(9):1343-52.

Chirapathomsakul D, Sastravaha P, Jansisyanont P. A review of odontogenic keratocysts and the behavior of recurrences. Oral Surg Oral Med Oral Pathol Oral Radiol Endod. 2006 Jan;101(1):5-9.

Choudry Q, Patel HC, Gurusinghe NT, Evans DG. Radiationinduced brain tumours in nevoid basal cell carcinoma syndrome: implications for treatment and surveillance. Childs Nerv Syst 2007;23:133-6.

Cowan R, Hoban P, Kelsey A, Birch JM, Gattamaneni R, Evans DG. The gene for the naevoid basal cell carcinoma syndrome acts as a tumour-suppressor gene in medulloblastoma. Br J Cancer. 1997;76(2):141-5.

Crivelini MM, de Araújo VC, de Sousa SO, de Araújo NS. Cytokeratins in epithelia of odontogenic neoplasms. Oral Dis. 2003 Jan;9(1):1-6.

Crowley TE, Kaugars GE, Gunsolley JC. Odontogenic keratocysts: a clinical and histologic comparison of the parakeratin and orthokeratin variants. J Oral Maxillofac Surg 1992; 50: 2226.

De Laurenzi V, Melino G. Evolution of functions within the p53/p63/p73 family. Ann N Y Acad Sci. 2000;926:90-100.

Pasca di Magliano M, Hebrok M. Nat Rev Cancer. 2003 Dec;3(12):903-11. Hedgehog signalling in cancer formation and maintenance. 
Donoff RB, Harper E, Guralnick WC. Collagenyticactivity in keratocysts. J Oral Surg 1972;30:879- 84;

Evangelista M, Tian H, de Sauvage FJ. The hedgehog signaling pathway in cancer. Clin Cancer Res. 2006 Oct 15;12(20 Pt 1):5924-8.

Evans DG, Farndon PA, Burnell LD, Gattamaneni HR, Birch JM. The incidence of Gorlin syndrome in 173 consecutive cases of medulloblastoma. Br J Cancer 1991: 64: 959-1.

Evans DG, Ladusans EJ, Rimmer S, Burnell LD, Thakker N, Farndon PA. Complications of the naevoid basal cell carcinoma syndrome: results of a population based study. J Med Genet 1993;30:460-4.

Evans DG, Farndon PA. In: Pagon RA, Bird TD, Dolan CR, Stephens K, editors. GeneReviews [Internet]. Nevoid Basal Cell Carcinoma Syndrome. Seattle (WA): University of Washington, Seattle; 2010; 20.

Farndon PA, Del Mastro RG, Evans DG, Kilpatrick MW: Location of gene for Gorlin syndrome. Lancet 1992; 339:581-2.

Fregnani ER, Fillipi RZ, Oliveira CR, Vargas PA, Almeida OP. Odontomas and ameloblastomas: variable prevalences around the world? Oral Oncol. 2002 Dec;38(8):807-8.

González-Alva P, Tanaka A, Oku Y, Yoshizawa D, Itoh S, Sakashita H, Ide F, Tajima Y, Kusama K. Keratocystic odontogenic tumor: a retrospective study of 183 cases. J Oral Sci. 2008 Jun;50(2):205-12.

Gurgel CA, Ramos EA, Azevedo RA, Sarmento VA, da Silva Carvalho AM, dos Santos JN. Expression of Ki-67, p53 and p63 proteins in keratocyst odontogenic tumours: an immunohistochemical study. J Mol Histol. 2008 Jun;39(3):311-6.

Habibi A, Jafarzadeh H. Nevoid basal cell carcinoma syndrome: a 17-year study of 19 cases in Iranian population (1991-2008). J Oral Pathol Med 2010;39:677-80.

Hyun HK, Hong SD, Kim JW. Recurrent keratocystic odontogenic tumor in the mandible: a case report and literature review. Oral Surg Oral Med Oral Pathol Oral Radiol Endod. 2009 Aug;108(2):e7-10. 
Jones EA, Sajid MI, Shenton A, Evans DG. Basal cell carcinomas in gorlin syndrome: a review of 202 patients. J Skin Cancer. 2011;2011:1-6.

Jordan RC. Histology and ultrastructural features of the odontogenic keratocyst. Oral Maxillofac Surg Clin North Am. 2003 Aug;15(3):325-33.

Kimonis VE, Goldstein AM, Pastakia B, Yang ML, Kase R, DiGionvannaJJ, et al. Clinical manifestations in 105 persons with nevoid basal cell carcinoma syndrome. Am J Med Genet 1997: 69:299-308.

Kuroyanagi N, Sakuma H, Miyabe S, Machida J, Kaetsu A, Yokoi M, Maeda H, Warnakulasuriya S, Nagao T, Shimozato K. Prognostic factors for keratocystic odontogenic tumor (odontogenic keratocyst): analysis of clinico-pathologic and immunohistochemical findings in cysts treated by enucleation. Oral Pathol Med. 2009;38(4):386-92.

Lam KY, Chan AC. Odontogenic keratocysts: a clinicopathological study in Hong Kong Chinese. Laryngoscope. 2000 Aug;110(8):1328-32.

Li TJ, Browne RM, Matthews JB. Epithelial cell proliferation in odontogenic keratocysts: a comparativeimmunocytochemical study of Ki67 in simple, recurrent and basal cell naevus syndrome (BCNS)-associated lesions. J Oral Pathol Med. 1995 May;24(5):221-6.

Li TJ, Browne RM, Prime SS, Paterson IC, Matthews JB. p53 expression in odontogenic keratocyst epithelium. J Oral Pathol Med. 1996 May;25(5):249-55.

Li TJ, Kitano M, Chen M, Itoh T, Kawashima K, Sugihara K et al. Orthokeratinized odontogenic cyst: a clinicopathological and immunocytochemical study of 15 cases. Histopathology 1998; 32: 242-51.

Lo Muzio L, Nocini P, Bucci P, Pannone G, Consolo U, Procaccini M. Early diagnosis of nevoid basal cell carcinoma syndrome. J Am Dent Assoc 1999, 130:669-4.

Lo Muzio L. Nevoid basal cell carcinoma syndrome (Gorlin syndrome). Orphanet J Rare Dis. 2008;3:32.

Lombardi T, Odell EW, Morgan PR. p53 immunohistochemistry of odontogenic keratocysts in relation to recurrence, basal-cell budding and basal-cell naevus syndrome Arch Oral Biol. 1995;40(12):1081-4. 
Luo HY, Li TJ. Odontogenic tumors: a study of 1309 cases in a Chinese population. Oral Oncol. 2009;45(8):706-11.

Manfredi M, Vescovi P, Bonanini M, Porter S. Nevoid basal cell carcinoma syndrome: a review of the literature. Int J Oral Maxillofac Surg. 2004;33(2):117-24.

Marin-gutzke M, Sanchez-olaso A, Berenguer B, Gonzalez B, Rodriguez P, De salamanca JE et al. Basal cell carcinoma in childhood after radiation therapy: case report and review. Ann Plast Surg 2004;53:593-5.

Mateus GC, Lanza GH, de Moura PH, Marigo Hde A, Horta MC. Cell proliferation and apoptosis in keratocystic odontogenic tumors. Med Oral Patol Oral Cir Bucal. 2008;13(11).

Meara JG, Shah S, Li KK, Cunningham MJ. The odontogenic keratocyst: a 20-year clinicopathologic review. Laryngoscope. 1998;108(2):280-3.

Meara JG, Pilch BZ, Shah SS, Cunningham MJ. Cytokeratin expression in the odontogenic keratocyst. J Oral Maxillofac Surg. 2000;58(8):862-5.

Mendes RA, Carvalho JF, van der Waal I. Biological pathways involved in the aggressive behavior of the keratocystic odontogenic tumor and possible implications for molecular oriented treatment - an overview. Oral Oncol 2010a;46:19-24.

Mendes RA, Carvalho JF, van der Waal I Characterization and management of the keratocystic odontogenic tumor in relation to its histopathological and biological features. Oral Oncol. 2010b;46(4):219-25.

Mendes RA, Carvalho JF, van der Waal I. A comparative immunohistochemical analysis of COX-2, p53, and Ki-67 expression in keratocystic odontogenic tumors. Oral Surg Oral Med Oral Pathol Oral Radiol Endod. 2011;111(3):333-9.

Moll R, Divo M, Langbein L. The human keratins: biology and pathology. Histochem Cell Biol. 2008;129(6):705-33.

Morgan TA, Burton CC, Qian F. A retrospective review of treatment of the odontogenic keratocyst. J Oral Maxillofac Surg 2005; 63(5):635-9.

Mosqueda-Taylor A, Ledesma-Montes C, Caballero-Sandoval S, Portilla-Robertson J, RuízGodoy Rivera LM, Meneses-García A. Odontogenic tumors in Mexico: a collaborative 
retrospective study of 349 cases. Oral Surg Oral Med Oral Pathol Oral Radiol Endod. 1997;84(6):672-5.

Myoung H, Hong SP, Hong SD, Lee JI, Lim CY, Choung PH, Lee JH, Choi JY, Seo BM, Kim MJ Odontogenic keratocyst: Review of 256 cases for recurrence and clinicopathologic parameters. Oral Surg Oral Med Oral Pathol Oral Radiol Endod. 2001;91(3):328-33.

Ochsenius G, Ortega A, Godoy L, Peñafiel C, Escobar E. Odontogenic tumors in Chile: a study of 362 cases. J Oral Pathol Med. 2002;31(7):415-20.

Ogden GR, Chisholm DM, Kiddie RA, Lane DP. p53 protein in odontogenic cysts: increased expression in some odontogenic keratocysts. J Clin Pathol. 1992;45(11):1007-10.

Ohki K, Kumamoto H, Ichinohasama R, Sato T, Takahashi N, Ooya K. PTC gene mutations and expressions of SHH, PTC, SMO and GLI-1 in odontogenic keratocysts. Int J Oral Maxillofac Surg 2004; 33:584-592.

Osterne RL, Brito RG, Alves AP, Cavalcante RB, Sousa FB. Odontogenic tumors: a 5-year retrospective study in a Brazilian population and analysis of 3406 cases reported in the literature. Oral Surg Oral Med Oral Pathol Oral Radiol Endod. 2011;111(4):474-81.

Pasca di Magliano M, Hebrok M. Hedgehog signalling in cancer formation and maintenance. Nat Rev Cancer. 2003;3(12):903-11.

Philipsen HP. Om Keratocystedr (Kolesteratomer) and kaeberne. Tandlaegebladet 1956; 60:963-71.

Philipsen HP, Fejerskov O, Donatsky O, Hjorting-Hansen E. Ultrastructure of epithelial lining of keratocysts in nevoid basal cell carcinoma syndrome. Int J Oral Surg 1976;5:71- 81

Pogrel MA. The use of liquid nitrogen cryotherapy in the management of locally aggressive bone lesions. J Oral Maxillofac Surg. 1993;51(3):269-73; discussion 274.

Santos JN, Pinto LP, de Figueredo CR, de Souza LB. Odontogenic tumors: analysis of 127 cases. Pesqui Odontol Bras. 2001;15(4):308-13.

Santos JN, Oliveira GQ, Gurgel CA, de Souza RO, Sales CB, de Aguiar Pires

Valença Neto A, Ramos EA. Altered expression of cytokeratins in primary, recurrent and syndrome keratocystic odontogenic tumors. J Mol Histol. 2009;40(4):269-75. 
Shanley S, Ratcliffe J, Hockey A, Haan E, Oley C, Ravine D, Martin N, Wicking C, Chenevix-Trench G: Nevoid basal cell carcinoma syndrome: review of 118 affected individuals. Am J Med Genet 1994, 50:282-90.

Schmidt BL, Pogrel MA. The use of enucleation and liquid nitrogen cryotherapy in the management of odontogenic keratocysts. J Oral Maxillofac Surg. 2001 Jul;59(7):720-5; discussion 726-7.

Scholzen T, Gerdes J. The Ki-67 protein: from the known and the unknown. J Cell Physiol. 2000 Mar;182(3):311-22.

Shear M. The aggressive nature of the odontogenic keratocyst: is it a benign cystic neoplasm? Part 3. Immunocytochemistry of cytokeratin and other epithelial cell markers. Oral Oncol. 2002a;38(5):407-15.

Shear M. The aggressive nature of the odontogenic keratocyst: is it a benign cystic neoplasm? Part 2. Proliferation and genetic studies. Oral Oncol. 2002b;38(4):323-31.

Shear M. The aggressive nature of the odontogenic keratocyst: is it a benign cystic neoplasm? Part 1. Clinical and early experimental evidence of aggressive behaviour. Oral Oncol. 2002c;38(3):219-26.

Sriram G, Shetty RP. Odontogenic tumors: a study of 250 cases in an Indian teaching hospital. Oral Surg Oral Med Oral Pathol Oral Radiol Endod. 2008 Jun;105(6):e14-21.

Stoelinga PJ. Long-term follow-up on keratocysts treated according to a defined protocol. Int J Oral Maxillofac Surg 2001; 30(1):14-25.

Stoll C, Stollenwerk C, Riediger D, Mittermayer C, Alfer J. Cytokeratin expression patterns for distinction of odontogenic keratocysts from dentigerous and radicular cysts. J Oral Pathol Med. 2005 Oct;34(9):558-64.

Sun LS, Li XF, Li TJ. PTCH1 and SMO gene alterations in keratocystic odontogenic tumors. J Dent Res. 2008 Jun;87(6):575-9

Taipale J, Chen JK, Cooper MK, Wang B, Mann RK, Milenkovic L et al. Effects of oncogenic mutations in Smoothened and Patched can be reversed by cyclopamine. Nature 2000;406:1005-9. 
Tawfik MA, Zyada MM. Odontogenic tumors in Dakahlia, Egypt: analysis of 82 cases Oral Surg Oral Med Oral Pathol Oral Radiol Endod. 2010 Feb;109(2):e67-73.

Thosaporn W, Iamaroon A, Pongsiriwet S, Ng KH. A comparative study of epithelial cell proliferation between the odontogenic keratocyst, orthokeratinized odontogenic cyst, dentigerous cyst, and ameloblastoma. Oral Dis 2004; 10: 22-6.

Tonietto L, Borges HO, Martins CA, Silva DN, Sant'ana Filho M. Enucleation and Liquid Nitrogen Cryotherapy in the Treatment of Keratocystic Odontogenic Tumors: A Case Series. J Oral Maxillofac Surg. 2011;69(6):112-7.

Voorsmit RA, Stoelinga PJ, van Haelst UJ. The management of keratocysts. J Maxillofac Surg. 1981 Nov;9(4):228-36.

Vuahula E, Nikai H, ijuhin N, Ogawa I, Takata T, Koseki T, Tanimoto K. Jaw cysts with orthokeratinization: analysis of 12 cases. J Oral Pathol Med 1993; 22: 35-40.

Wallin JL, Tanna N, Misra S, Puri PK, Sadeghi N. Sinonasal carcinoma after irradiation for medulloblastoma in nevoid basal cell carcinoma syndrome. Am J Otolaryngol 2007;28(5):360-2.

Wicking C, Smyth I, Bale A. The hedgehog signalling pathway in tumorigenesis and development. Oncogene. 1999;18(55):7844-51.

Williams JA, Guicherit OM, Zaharian BI, Xu Y, Chai L, Wichterle H et al. Identification of a small molecule inhibitor of the hedgehog signaling pathway: effects on basal cell carcinomalike lesions.Proc Natl Acad Sci USA 2003;100:4616-21

Woolgar JA, Rippin JW, Browne RM. The odontogenic keratocyst and its occurrence in the nevoid basal cell carcinoma syndrome. Oral Surg Oral Med Oral Pathol. 1987;64(6):727-30.

Wright JM. The odontogenic keratocyst: orthokeratinized variant. Oral Surg Oral Med Oral Pathol. 1981;51(6):609-18.

Yates, F. "Contingency table involving small numbers and the $\chi^{2}$ test". Supplement to the Journal of the Royal Statistical Society 1934 1(2): 217-35.

Zecha JA, Mendes RA, Lindeboom VB, van der Waal I. Recurrence rate of keratocystic odontogenic tumor after conservative surgical treatment without adjunctive therapies - A 35year single institution experience. Oral Oncol. 2010;46(10):740-2. 
Zhang H, Ping XL, Lee PK, Wu XL, Yao YJ, Zhang MJ, Silvers DN, Ratner D, Tsou HC. Role of PTCH and p53 Genes in Early-Onset Basal Cell Carcinoma. Am J Pathol. 2001;158(2): 381-5.

Zhao YF, Wei JX, Wang SP. Treatment of odontogenic keratocysts: a follow-up of 255 Chinese patients. Oral Surg Oral Med Oral Pathol Oral Radiol Endod. 2002;94(2):151-6. 
APÊNDICE A - Dados clínicos dos pacientes com TOQCs.

\section{A) DADOS CLÍNICOS DO PACIENTE}

Identificação:

Dados Gerais:

Nome:

RGH: Data admissão:

1. Idade: 2. Data Nascimento:

3. Etnia: 1- Branca 2- negra 3- parda 4- amarela 5- NI

4. Sexo: 1- masculino 2- Feminino

5. Queixa: 1-inchaço 2-dor 3-parestesia 4-nenhuma 5-outra 6-NI

6. Tempo de queixa: meses

7. Biópsia prévia: 1- sim 2- não

8. Data biópsia prévia: / Laudo:

9. Tratamento prévio: 1- nenhum 2- ressecção 3- marsupialização 4- curetagem 5- enucleação 6- enucleação+crio 7- enucleação+carnoy 8- curetagem+criot 9- curetagem+carnoy 10 - NI

10. Data tratamento prévio: /Laudo:

11. Número de TOQCs:

12. Data última informação da estômatologia:

13. Situação da última informação: 1-vivo s/doença 2-vivo c/ doença 3- óbito 4- perdido de vista

14.Data do óbito:

15. Associação com SCNBC: 1-sim 2-não 


\section{B) DADOS CLÍNICOS DO TUMOR:}

Lesão $n^{\circ}$

1. Ectoscopia: 1-simetria facial 2-assimetria facial 3-linfonodos palpáveis 4- outros 5-NI

2. Oroscopia: 1-abaulamento 2-nódulo 3-fístula 4-sem alterações 5-outros 6-NI

3.Localização:1-mand corpo D 2-mand corpo E 3-mand ramo D 4-mand ramo E 5-mand ant 6-maxila ant 7-maxila post D 8-maxila post E 0- NI

4.Tamanho clínico: $\mathrm{cm}$

5. Tamanho radiográfico: $\mathrm{cm}$

6. Padrão radiográfico: 1-unilocular 2-multilocular 3-ambos 4-NI

7. Envolvimento das corticais: 1- preserva 2- expande 3-rompe 4-NI

8. Tipo de associação com dentes: 1- deslocamento dental 2- envolvimento tumoral 3 Reabsorção radicular 4-Não há $\quad$ 5-NI

9. HD: 1-TOQC 2-cisto dentígero 3- outro cisto 4- ameloblastoma 5-outro tumor 0-NI

10.Tipo de tratamento: 1- nenhum 2- ressecção 3- marsupialização 4- curetagem 5enucleação 6- enucleação+crio 7- enucleação+carnoy 8- curetagem+criot 9curetagem+carnoy 10 - NI

11.Data do tratamento:

12. $\mathrm{N}^{\mathrm{o}} \mathrm{AP}$ : /Laudo:

13. Recorrência: 1-sim 2- não

14.Data da recorrência:

$1-$ /AP:

$2-$ /AP:

$3-$ /AP: 
C) MANIFESTAÇÕES CLÍNICAS DA SCNBC

1. CBC:

2. Calcificação da foice cerebral

3. ““"pits”” palmares e/ou plantares

4. Costelas bífidas, fusionadas ou alargadas:

5. Macrocefalia

6. Malformações congênitas orofaciais:

7. Outras anormalidades esqueléticas:

8. Anormalidades radiológicas:

9. Fibroma de ovário

10. Meduloblastoma

11. Parente de $1^{\circ}$ grau com SCNBC:

12. Outras: 
APÊNDICE B - Porcentagem da marcação do p53 e ki-67 dos 90 casos avaliados.

\begin{tabular}{|c|c|c|c|c|c|c|c|c|c|}
\hline P53 & $0 \%$ & $1+\%$ & $2+\%$ & $3+\%$ & Ki-67 & $0 \%$ & $1+\%$ & $2+\%$ & $3+\%$ \\
\hline 155272 & 57.9864 & 34.2691 & 6.87318 & 0.871249 & 155272 & 51.9646 & 18.5658 & 11.4931 & $\begin{array}{l}17.9764 \\
\end{array}$ \\
\hline 156764 & 22.9931 & 25.8672 & 31.9128 & 19.227 & 156764 & 55.4337 & 20.5384 & \begin{tabular}{|l|}
10.7677 \\
\end{tabular} & 13.2602 \\
\hline 171726 & 63.4286 & 20.6667 & 10.1905 & 5.71429 & 171726 & 65.792 & 18.4645 & 7.48299 & 8.26045 \\
\hline 182306 & 75.2678 & 16.8452 & 5.64752 & 2.23953 & 182306 & 73.5435 & 9.36008 & 3.15186 & 13.9446 \\
\hline $198224 \mathrm{~A}$ & 41.7897 & 27.7675 & 23.3395 & 7.10332 & $198224 \mathrm{~A}$ & 74.7307 & 15.8668 & 4.11361 & 5.28893 \\
\hline 208796 & 53.0214 & 22.807 & 16.5692 & 7.60234 & 208796 & 72.2821 & 5.97453 & 4.01567 & 17.7277 \\
\hline 214593 & 89.2505 & 9.76331 & 0.788955 & 0.197239 & 214593 & 84.608 & 6.78776 & 4.49331 & 4.1109 \\
\hline 223124 & 56.9457 & 26.6789 & 12.3275 & 4.04784 & 223124 & 68.8679 & 17.7358 & 6.88679 & 6.50943 \\
\hline 228081 & 21.8964 & 30.4008 & 31.8671 & 15.8358 & 228081 & 62.4385 & 25.4671 & 7.66962 & 4.42478 \\
\hline 228188 & 65.4369 & 26.0194 & 7.47573 & 1.06796 & 228188 & 70.0283 & 9.89632 & 4.24128 & 15.8341 \\
\hline 241046 & 53.1894 & 30.3238 & 13.5427 & 2.94406 & 241046 & 81.1808 & 9.13284 & 2.49077 & 7.19557 \\
\hline 243318 & 38.6916 & 30. & 21.5888 & 9.71963 & 243318 & 64.3478 & 18.6473 & 6.47343 & 10.5314 \\
\hline 244319 & 50.5988 & 36.6267 & 10.8782 & 1.89621 & 244319 & 86.0656 & 4.28051 & 3.00546 & 6.64845 \\
\hline 253214 & 66.6667 & 20.8941 & 10.5928 & 1.84645 & 253214 & 68.4932 & 13.9922 & 5.08806 & 12.4266 \\
\hline 257190 & 60.4536 & 26.0355 & 11.9329 & 1.57791 & 257190 & 79.7156 & 9.19431 & 6.72986 & 4.36019 \\
\hline 262486 & 74.0038 & 19.26 & 4.74383 & 1.99241 & 262486 & 76.6382 & 17.3789 & 2.65907 & 3.32384 \\
\hline 263418 & 54.9188 & 29.4174 & 10.9838 & 4.68004 & 263418 & 86.9606 & 5.25328 & 3.93996 & 3.84615 \\
\hline 266703 & 51.6619 & 25.831 & 17.284 & 5.22317 & 266703 & 87.5977 & 6.34766 & 2.24609 & 3.80859 \\
\hline 268216 & 33.112 & 41.8406 & 21.4421 & 3.60531 & 268216 & 91.0433 & 3.05118 & 1.77165 & 4.13386 \\
\hline 271865 & 51.3672 & 38.2813 & \begin{tabular}{|l|}
8.30078 \\
\end{tabular} & 2.05078 & 271865 & 76.338 & 5.16432 & 3.47418 & 15.0235 \\
\hline 277660 & 49.3874 & 35.8153 & 12.5353 & 2.26202 & 277660 & 58.6304 & 16.8856 & 9.66229 & 14.8218 \\
\hline 278756 & 32.9469 & 34.0097 & 25.1208 & 7.92271 & 278756 & 81.9687 & 11.1316 & 2.5759 & 4.32383 \\
\hline 286351 & 41.9227 & 24.3806 & 23.4886 & 10.2081 & 286351 & 79.3396 & 10.1887 & 4.71698 & 5.75472 \\
\hline 289874 & 29.9522 & 20.7656 & 24.2105 & 25.0718 & 289874 & 42.1053 & 15.4971 & 20.3704 & 22.0273 \\
\hline $290053 \mathrm{~A}$ & 36.4245 & 13.3843 & 22.6577 & 27.5335 & $290053 \mathrm{~A}$ & 49.1592 & 26.2117 & 14.5401 & 10.089 \\
\hline 290053 B & 28.4608 & 23.0397 & 37.5605 & 10.939 & $290053 \mathrm{~B}$ & 53.4517 & 22.288 & 8.57988 & 15.6805 \\
\hline 293749B & 56.2136 & 20.3883 & 15.9223 & 7.47573 & 293749B & 69.3281 & 13.3398 & 7.78968 & 9.54236 \\
\hline 300849 & 31.8403 & 43.2327 & 18.9873 & 5.93963 & 300849 & 73.2938 & 6.72601 & 4.45104 & 15.5292 \\
\hline 303159 & 39.6654 & 33.4646 & 22.1457 & 4.72441 & 303159 & 72.9107 & 10.4707 & 6.62824 & 9.99039 \\
\hline $307059 \mathrm{~A}$ & 51.6974 & 33.9476 & 9.79631 & 4.55868 & $307059 \mathrm{~A}$ & 70.1261 & 14.937 & 3.87973 & 11.0572 \\
\hline 308879 & 67.5024 & 26.5188 & 5.68949 & 0.289296 & 308879 & 83.8077 & 7.85083 & 3.43474 & 4.90677 \\
\hline 309754 & 65.7843 & 28.8235 & 3.92157 & 1.47059 & 309754 & 88.6342 & 5.34862 & 4.39351 & 1.62369 \\
\hline $313816 \mathrm{~A}$ & 98.5192 & 1.28332 & 0.197433 & 0. & $313816 \mathrm{~A}$ & 93.2406 & 4.07555 & 1.49105 & 1.19284 \\
\hline $315587 \mathrm{~A}$ & 65.005 & 22.7318 & 8.47458 & 3.78863 & $315587 \mathrm{~A}$ & 82.7255 & 5.75816 & 3.64683 & 7.86948 \\
\hline $316351 \mathrm{~A}$ & 40.4738 & 26.9497 & 23.9882 & 8.58835 & $316351 \mathrm{~A}$ & 68.4262 & 12.0235 & 4.78983 & 14.7605 \\
\hline 325065 & 61.2127 & 15.0144 & \begin{tabular}{|l|}
11.3571 \\
\end{tabular} & 12.4158 & 325065 & 63.0178 & 13.6095 & 8.6785 & 14.6943 \\
\hline 332277 & 97.6789 & 2.12766 & 0.193424 & 0. & 332277 & 94.294 & 3.77176 & 1.35397 & 0.580271 \\
\hline 336658 & 41.4032 & 36.7589 & 17.0949 & 4.74308 & 336658 & 77.821 & 12.4514 & 4.0856 & 5.64202 \\
\hline $338569 \mathrm{~A}$ & 62.9482 & 23.3068 & 9.36255 & 4.38247 & $338569 \mathrm{~A}$ & 64.1176 & 6.96078 & 6.07843 & 22.8431 \\
\hline $340448 \mathrm{~A}$ & 81.1891 & 14.9123 & 3.11891 & 0.779727 & $340448 \mathrm{~A}$ & 78.0822 & 13.4051 & 5.28376 & 3.22896 \\
\hline $340630 \mathrm{~A}$ & 68.0193 & 25.314 & 5.89372 & 0.772947 & $340630 \mathrm{~A}$ & 88.5939 & 7.76794 & 3.04818 & 0.589971 \\
\hline B97-157D1 & 72.4172 & 23.5867 & 3.60624 & 0.389864 & B97-157D1 & 80.9298 & 9.86717 & 4.0797 & 5.12334 \\
\hline B97-157E & 42.6471 & 35.9804 & 18.8235 & 2.54902 & B97-157E & 59.042 & 26.4907 & 7.03812 & 7.42913 \\
\hline B97-1267A & 71.9466 & 23.2824 & 3.72137 & 1.04962 & B97-1267A & 88.9872 & 5.70305 & 2.7532 & 2.55654 \\
\hline B97-2913 B1 & 77.0606 & 20.2582 & 2.18471 & 0.496524 & $\begin{array}{l}\text { B97-2913 } \\
\text { B1 } \\
\end{array}$ & 79.2695 & 9.77295 & 6.31787 & 4.63968 \\
\hline B97-2992 & 70.5191 & 19.2948 & 8.81489 & 1.3712 & B97-2992 & 88.5742 & 7.61719 & 2.63672 & 1.17188 \\
\hline B97-5927B & 29.3489 & 23.1293 & 32.4587 & 15.0632 & B97-5927B & 81.7729 & 7.37052 & 3.78486 & 7.07171 \\
\hline 720807 & 53.493 & 31.4371 & 11.6766 & 3.39321 & 720807 & 74.3564 & 9.50495 & 8.71287 & 7.42574 \\
\hline B98-06572 B1 & 78.1188 & 17.5248 & 4.05941 & 0.29703 & $\begin{array}{l}\text { B98-06572 } \\
\text { B1 }\end{array}$ & 87.3767 & 11.5385 & 1.08481 & 0. \\
\hline B99-2860B & 61.8636 & 29.0106 & 7.01249 & 2.11335 & B99-2860B & 92.2625 & 6.36631 & 1.3712 & 0. \\
\hline
\end{tabular}




\begin{tabular}{|c|c|c|c|c|c|c|c|c|c|}
\hline B99-3637 C & 98.2724 & 1.72764 & 0. & 0. & B99-3637 C & 90.4762 & 7.04762 & 2. & 0.47619 \\
\hline B99-4922A & 91.3894 & 7.63209 & 0.978474 & 0. & B99-4922A & 92.1937 & 5.73123 & 1.08696 & 0.988142 \\
\hline B99-6305 & 41.0206 & 46.1237 & 11.9725 & 0.883219 & B99-6305 & 85. & 6.4 & 4.2 & 4.4 \\
\hline B99-06345B & 84.7425 & 12.828 & 2.42954 & 0. & B99-06345B & 81.9231 & 6.05769 & 5.19231 & 6.82692 \\
\hline B99-6346B1 & 43.0244 & 31.122 & 19.5122 & 6.34146 & B99-6346B1 & 63.4387 & 18.7747 & 6.71937 & 11.0672 \\
\hline B99-8916 A & 47.3108 & 39.5418 & 11.1554 & 1.99203 & B99-8916 A & 79.822 & 13.7488 & 4.54995 & 1.87933 \\
\hline BA0-921 B & 59.921 & 32.1816 & 5.62685 & 2.27048 & BA0-921 B & 73.0769 & 11.7357 & 5.81854 & 9.36884 \\
\hline BA0-5784A & 95.1195 & 4.68127 & 0.199203 & 0. & BA0-5784A & 87.3405 & 7.55643 & 4.02355 & 1.07949 \\
\hline BA0-10394A2 & 82.5581 & 14.8256 & 2.13178 & 0.484496 & $\begin{array}{l}\text { BA0- } \\
10394 A 2\end{array}$ & 82.5536 & 11.2086 & 4.77583 & 1.46199 \\
\hline BA1-4921A & 98.6667 & 1.33333 & 0. & 0. & BA1-4921A & 97.8947 & 1.5311 & 0.574163 & 0. \\
\hline BA1-5067A & 73.187 & 24.0458 & 2.76718 & 0. & BA1-5067A & 85.2621 & 7.22057 & 4.64886 & 2.86845 \\
\hline BA1-8386C & 97.973 & 1.5444 & 0.482625 & 0. & BA1-8386C & 94.4554 & 2.87129 & 2.27723 & 0.39604 \\
\hline BA2-1547 A & 99.4203 & 0.57971 & 0. & 0. & BA2-1547 A & 99.5131 & 0.292113 & 0.194742 & 0. \\
\hline BA2-2895 & 71.0088 & 21.7434 & 5.87659 & 1.3712 & BA2-2895 & 94.1757 & 3.5538 & 1.87562 & 0.394867 \\
\hline BA3-5239B & 89.5257 & 9.98024 & 0.494071 & 0. & BA3-5239B & 86.3939 & 8.18268 & 4.56708 & 0.856327 \\
\hline BA3-7211B1 & 75.1485 & 21.9802 & 2.67327 & 0.19802 & $\begin{array}{l}\text { BA3- } \\
7211 B 1\end{array}$ & 76.4532 & 20.0985 & 2.75862 & 0.689655 \\
\hline BA4-10744A & 80.2734 & 18.75 & 0.976563 & 0. & $\begin{array}{l}\text { BA4- } \\
10744 \mathrm{~A} \\
\end{array}$ & 71.1881 & 20.297 & 5.0495 & 3.46535 \\
\hline BA4-11421C & 64.0927 & 29.1506 & 6.37066 & 0.3861 & $\begin{array}{l}\text { BA4- } \\
11421 C\end{array}$ & 75.0969 & 18.1202 & 5.03876 & 1.74419 \\
\hline BA5-4167B & 63.0097 & 32.4272 & 4.27184 & 0.291262 & BA5-4167B & 59.1045 & 25.7711 & 13.2338 & 1.89055 \\
\hline BA5-8552 & 31.4508 & 26.777 & 29.3087 & 12.4635 & BA5-8552 & 73.5939 & 12.2974 & 5.91039 & 8.19828 \\
\hline BA6-1629 & 62.2093 & 32.9457 & 4.06977 & 0.775194 & BA6-1629 & 87.0389 & 5.78265 & 3.19043 & 3.98804 \\
\hline BA6-10171 & 65. & 30. & 4.51923 & 0.480769 & BA6-10171 & 76.6667 & 7.64706 & 4.41176 & 11.2745 \\
\hline BA7-0394 & 97.862 & 1.94363 & 0.194363 & 0. & BA7-0394 & 91.8812 & 5.94059 & 1.9802 & 0.19802 \\
\hline 821324 AA & 59.9606 & 21.3018 & 12.8205 & 5.91716 & 821324 AA & 83.9 & 11.1 & 1.8 & 3.2 \\
\hline 830860 AA & 66.075 & 26.3314 & 6.50888 & 1.08481 & 830860 AA & 71.9844 & 8.36576 & 4.96109 & 14.6887 \\
\hline $832488 \mathrm{AB}$ & 56.8493 & 28.4736 & 9.58904 & 5.08806 & $832488 \mathrm{AB}$ & 63.745 & 6.4741 & 5.87649 & 23.9044 \\
\hline $905126 \mathrm{AC}$ & 68.1818 & 22.9249 & 5.5336 & 3.35968 & $905126 \mathrm{AC}$ & 79.4821 & 8.36653 & 2.78884 & 9.36255 \\
\hline 905126 AG & 84.5703 & 13.5742 & 1.46484 & 0.390625 & $905126 \mathrm{AG}$ & 87.3062 & 5.03876 & 3.87597 & 3.77907 \\
\hline 906861 AA & 30.8349 & 34.0607 & 27.0398 & 8.06452 & $906861 \mathrm{AA}$ & 72.9941 & 11.8395 & 5.18591 & 9.98043 \\
\hline 920033 AA & 51.001 & 36.1296 & 11.0582 & 1.81125 & 920033 AA & 76.7928 & 7.47012 & 4.18327 & 11.5538 \\
\hline $941457 \mathrm{AB}$ & 44.1147 & 29.3769 & 20.9693 & 5.53907 & $941457 \mathrm{AB}$ & 65.7658 & 8.10811 & 6.40641 & 19.7197 \\
\hline $941457 \mathrm{AD}$ & 54.7459 & 30.3931 & 12.9434 & 1.91755 & $941457 \mathrm{AD}$ & 63.4193 & 14.2311 & 5.82617 & 16.5234 \\
\hline $944141 \mathrm{AA}$ & 22.333 & 39.3819 & 34.7956 & 3.48953 & $944141 \mathrm{AA}$ & 61.6346 & 10.3846 & 6.34615 & 21.6346 \\
\hline $1004198 \mathrm{AA}$ & 47.6617 & 39.7015 & 11.1443 & 1.49254 & 1004198 AA & 69.8578 & 6.91943 & 5.30806 & 17.9147 \\
\hline $1004198 \mathrm{AB}$ & 51.6569 & 34.5029 & 11.2086 & 2.63158 & $1004198 \mathrm{AB}$ & 72.7184 & 7.08738 & 3.8835 & 16.3107 \\
\hline $1004198 \mathrm{AD}$ & 40.3679 & 52.9526 & 6.38916 & 0.290416 & $1004198 \mathrm{AD}$ & 79.5656 & 5.52813 & 4.93583 & 9.97038 \\
\hline $1004198 \mathrm{AF}$ & 85.6597 & 13.3843 & 0.764818 & 0.191205 & $1004198 \mathrm{AF}$ & 55.2326 & 20.3488 & 8.62403 & 15.7946 \\
\hline $1004198 \mathrm{AH}$ & 85.645 & 11.8332 & 1.4549 & 1.06693 & $1004198 \mathrm{AH}$ & 74.4412 & 5.345 & 5.53936 & 14.6744 \\
\hline 1017996 AA & 62.069 & 25.2874 & 9.09962 & 3.54406 & 1017996 AA & 63.1985 & 6.55106 & 5.39499 & 24.8555 \\
\hline
\end{tabular}


ANEXO A - Parecer do Comitê de Ética em Pesquisa

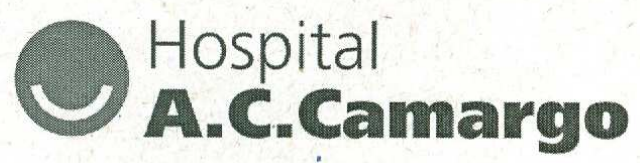

\section{Comitê de Ética em Pesquisa - CEP}

São Paulo, 18 de Novembro de 2009.

Ao

Dr. Fábio de Abreu Alves

Ref.: Projeto de Pesquisa ${ }^{\circ}$. 1322/09

"Avaliação dos parâmetros clínicos, histopatológicos e perfil imunoistoquímico do tumor odontogênico queratocístico associado ou não à Síndrome do Carcinoma Basocelular Nevóide".

Os membros do Comitê de Ética em Pesquisa em Seres Humanos da Fundação Antonio Prudente - Hospital do Câncer - A.C. Camargo/SP, em sua última reunião de 20/10/2009, aprovaram a realização do estudo em referência e tomaram conhecimento dos seguintes documentos:

Folha de Rosto para Pesquisa envolvendo Seres Humanos;

Termo de Compromisso do Pesquisador com Resoluções do CNS;

$>$ Termo de Dispensa do Consentimento Livre e Esclarecido;

$>$ Orçamento Financeiro detalhado;

$>$ Declaração de Ciência e Comprometimento do Departamento de Estomatologia;

$>$ Declaração de Ciência e Comprometimento do Departamento de Anatomia Patológica.

Informações a respeito do andamento do referido projeto deverão ser encaminhadas à assistente do CEP dentro de 12 meses.

Atenciosamente,

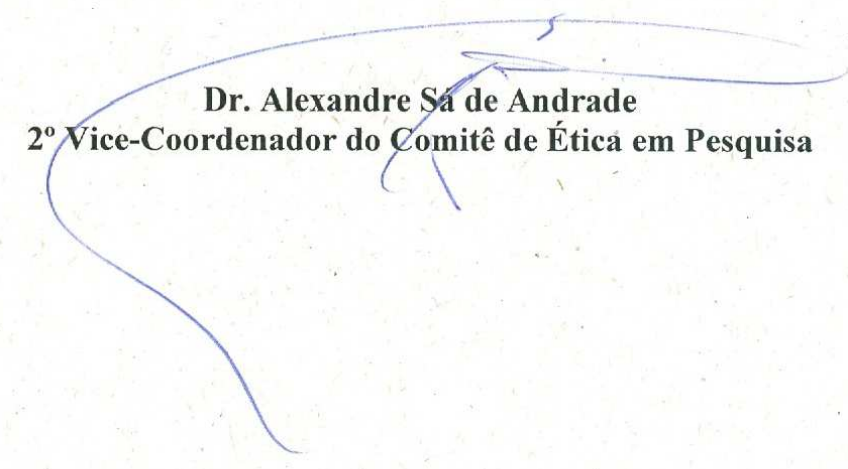

Rua Prof. Antônio Prudente, 211 - Liberdade - São Paulo - SP CEP 01509-900 - CNPJ 60.961.968/0001-06 